\title{
DIE GATTUNG STENOTHOE (CRUSTACEA, AMPHIPODA) IM MITTELMEER
}

\author{
von \\ GERTRAUD KRAPP-SCHICKEL \\ Zoologisches Forschungsinstitut und Museum A. Koenig, Bonn, B.R.Deutschland
}

\section{ZUSAMMENFASSUNG}

Ausgangssituation dieser Untersuchung war die Kenntnis von 11 nominellen Stenothoe-Arten im Mittelmeer. Von diesen wurde St. basphorana Sowinski, 1898, seit der Beschreibung nicht mehr wiedergefunden, von St. dactylipotens Chevreux, 1908, kannte man nur das $\$$, schließlich waren die Arten im Komplex St. dollfusi-gallensis-cattai kaum oder unklar voneinander abgegrenzt. Eigene Sammlungen aus der Adria, dem Jonischen Meer, Ligurien, der Tyrrhenis sowie den Küsten von Sizilien und Pantelleria erbrachten größere Serien von Stenothoe, die zu einer Revision der Gattung im Mittelmeerraum ermutigten.

St. dactylipotens erwies sich als Synonym von bosphorana; von St. antennulariae, die Della Valle, 1893, in einem juvenilen $\delta$ bekannt machte, wird das adulte $\delta$ erstmals abgebildet. Der Art St. cattai sensu Chevreux \& Fage, 1925, gab ich einen neuen Namen, wie schon vor mir drei Autoren forderten (denn St. cattai Stebbing, 1906, ist synonym zu St. gallensis Walker, 1904): St. eduardi n. sp. wird in of und $\%$ vollständig beschrieben und abgebildet. Die Abgrenzung der morphologisch sehr nahestehenden Arten dollfusi Chevreux, 1887, gallensis Walker, 1904, und eduardi n. sp. konnte dank der deutlich verschiedenen Okologie gelingen. Aus Livorno und Ischia lag mir eine „kleine Form von St. monoculoides" (schon Chevreux, 1911, hatte sie so bezeichnet) vor, die ich als eigene Art, St. elachista n. sp., abtrennen konnte. Schließlich verglich ich St. marina mediterranea von Ledoyer, 1973, mit atlantischem Material von St. m. marina (Bate, 1857) und kam zur Uberzeugung, daß die stärkere Bedornung der 5 Individuen aus Marseille noch innerhalb der Variationsbreite der Nominatform liegt.

Außer St. marina konnten alle Arten abgebildet werden. Die Arbeit wird von einem Bestimmungsschlüssel für mediterrane Stenothoe-Arten abgeschlossen, u. zw, antennulariae, bosphorana, cavimana, dollfusi, eduardi, elachista, gallensis, marina, monoculoides, tergestina und valida.

\section{EINLEITUNG}

Als bei den Vorbereitungen für das in Gemeinschaft mit sechs Kollegen geplante Bestimmungsbuch mediterraner Amphipoden alle bisher von mir gesammelten Stenothoiden zusammengestellt wurden, bemerkte ich drei Problem-Komplexe, die vorher noch gelöst werden mußten.

Aus Livorno und Napoli lagen mir kleine sandbewohnende Individuen in beträchtlichen Serien vor, die morphologisch große Ähnlichkeit $\mathrm{zu}$ Stenothoe monoculoides - manchmal aber auch zu St. tergestina - zeigten, jedoch wenig über $1 \mathrm{~mm}$ Körperlänge erreichten und nur $2-4$ große Eier enthielten, wogegen Weibchen von St. monoculoides über 20 Eier tragen kōnnen. Aus der Umgebung von Catania und Messina hatte ich Stenothoiden gesammelt, die lange Zeit in meiner Kartei unter ,dollfusi-gallensis" geführt wurden, ohne daß ich die Tiere mit Sicherheit einer Art zuschreiben konnte. Schließlich besaß ich aus Dalmatien Stenothoe ,dactylipotens"Material, das auch ein adultes Männchen enthielt, das bisher meines Wissens nach noch irgends abgebildet wurde.

So entstand im Handumdrehen eine Úbersicht zu allen mediterranen Stenothoe-Arten, die hier dargelegt werden soll.

Der Katalog von Barnard, 1958, bringt 10 Arten aus dem Mediterran, u. zw. Stenothoe antennulariae, bosphorana, cavimana, dactylipotens, dollfusi, gallensis, marina, monoculoides, tergestina und valida. Ledoyer, 1973, hob die Synonymie zwischen St. gallensis Walker und St. cattai Stebbing, die Barnard, 1955, gefordert hatte, wieder auf und erklärte St. cattai als gültige Art, was inzwischen auch schon andere Autoren vermutet hatten. Eine neue Art aus dem Mittelmeer wurde seit 1958 meines Wissens nicht beschrieben.

Außer St. marina waren alle genannten Arten in meiner Sammlung vertreten. Ich behandle sie in der Folge nach ihrer Ähnlichkeit gruppiert, 
was dann auch am Ende der Beschreibungen im Bestimmungsschlüssel seinen Niederschlag findet.

Um die fragliche kleine Stenothoe mit wenigen Eiern von St. tergestina sowie St. monoculoides abzugrenzen, ist es nötig, diese beiden Arten genau zu definieren.

Stenothoe tergestina (Nebeski, 1880).

Abb. $1-2$.

Probolium tergestinum Nebeski, 1880: 33, Taf. XIII Abb. 39. Stenothoe spinimana Chevreux, 1911: 197, Text-Abb. 7, Taf. XII Abb. 1-12; Chevreux \& Fage, 1925: 134, Abb. 133. Stenothoe tergestina; Ruffo, 1946: 51; Ruffo \& Wieser, 1952: $26-27$.

Diese Art ist in dem ganzen von mir besammelten Gebiet (Ligurien, Tyrrhenis, Sizilien, Pantelleria, Jonisches Meer und Adria) sehr häufiger Litoralbewohner, das Vorkommen konzentriert sich auf gut durchspülte Hochstrauchalgen der obersten 5 bis 10 Meter.

Meine Exemplare stimmen gut mit den Zeichnungen in Chevreux, 1911, sowie Chevreux \& Fage, 1925, überein, außer der Wiedergabe der dritten Coxalplatte in Chevreux \& Fage, die bei der hier behandelten Art wie bei allen übrigen parallele Kanten hat, nahezu rechteckig und vor allem relativ schmäler ist. Der Text der Beschreibung in Chevreux, 1911, betont, daß die zweiten und dritten Coxalplatten einander in der Form ähnlich sind, was noch eher stimmt als die Zeichnungen in Chevreux \& Fage, 1925.

Wichtig zur Konfrontation mit St. monoculoides ist das bestachelte Telson, zarte erste Antennen, die häufig länger als der halbe Körper werden, eine gleichmäßige posterodistale Propoduskontur bei beiden, vornehmlich aber den zweiten Gnathopoden, schwache Bestachelung, die keineswegs eine Palmarkante abgrenzt, sowie ein Pedunculus der dritten Uropoden, der etwa gleich lang wie der Ast ist.

Die Zeichnungen wurden nach Material aus Pantelleria und Sardinien (eigene Aufsammlungen) angefertigt.

Verbreitung. -

Atlantik: Trebeurden (Ärmelkanal) in Algen, sehr selten (Chevreux \& Fage, 1925); Dakar. Mediterran: franzōs. Küste von Banyuls bis Monaco; Ligurien, Tyrrhenis, Sizilien, Pantelleria,
Jonisches Meer, Adria, Tunesien, Bône, Cherchell.

Stenothoe monoculoides (Montagu, 1815).

Abb. 3.

Stenothoe monoculoides; Sars, 1893: 240-241, Taf. LXXXII Abb. 1; Della Valle, 1893: 568, Taf. LVIII Abb. 79 (partim); Stebbing, 1906: 196 (partim); Chevreux \& Fage, 1925: 133, Abb. 132; Schellenberg, 1942: 123-124, Abb. 10 ?

Aus der Tatsache, daß bei diesen Literaturzitaten gleich zweimal „partim" vorkommt, kann man ersehen, daß die Art nicht leicht abzugrenzen scheint. Bedenkt man dagegen, daß außer cavimana keine andere bisher bekannte mediterrane Art ein unbewehrtes Telson hat (es setzen überhaupt keine Dornen an, dagegen sind apikolateral zwei kleine Borsten zu erkennen), so ist dies schon eine große Hilfe.

Der Habitus ist gedrungen, die ersten Antennen sind kürzer als der halbe Körper, Gnathopod $2(\sigma, \&)$ hat eine deutliche Stachelgruppe, die die - außerdem durch einen Knick in der Propoduskontur verdeutlichte - Palma definiert. Bei einigen reifen Individuen war Stachelgruppe wie Knick auch an den ersten Gnathopoden zu erkennen. Schließlich ist der Pedunculus der dritten Uropoden viel kürzer als der Uropodenast.

Der von mir gezeichnete Habitus eines $3 \mathrm{~mm}$ großen, 21 Eier tragenden Weibchens bildet atlantisches Material ab (aus Cork, Irland). Die Detailzeichnungen stammen von der Insel Khios (Ägäis) und zeigen ein $1,5 \mathrm{~mm}$ großes $\delta$. Beide Individuen wurden von Allan Myers (Cork) gesammelt, und beide stimmen perfekt mit meinen Serien aus Rovinj, Taranto, Messina, Catania, Pantelleria sowie Napoli überein, mit Ausnahme des 1 . Gnathopoden, der nur selten so ausgeprägt bestachelt zu finden war.

Verbreitung. -

Atlantik: Norwegen bis Troms $\varnothing$, Kattegat, Brit. Inseln, Ärmelkanal, französ. Küste, Azoren, Teneriffa (Kanar. Inseln); 0-80 m. Mediterran: franzōs. Küste von Sète bis Villefranche, Sardinien, Napoli, Sizilien, Pantelleria, Malta, Taranto, Adria. Ceylon. Rotes Meer.

Stenothoe elachista n. sp. Abb. $4-6$.

Material. -

Fünf Individuen von Livorno (Ligurien: $43^{\circ} 33 \times \mathrm{N} 10^{\circ} 12^{\prime} 45^{\prime \prime}$ 
BIJDRAGEN TOT DE DIERKUNDE, 46 (1) - 1976
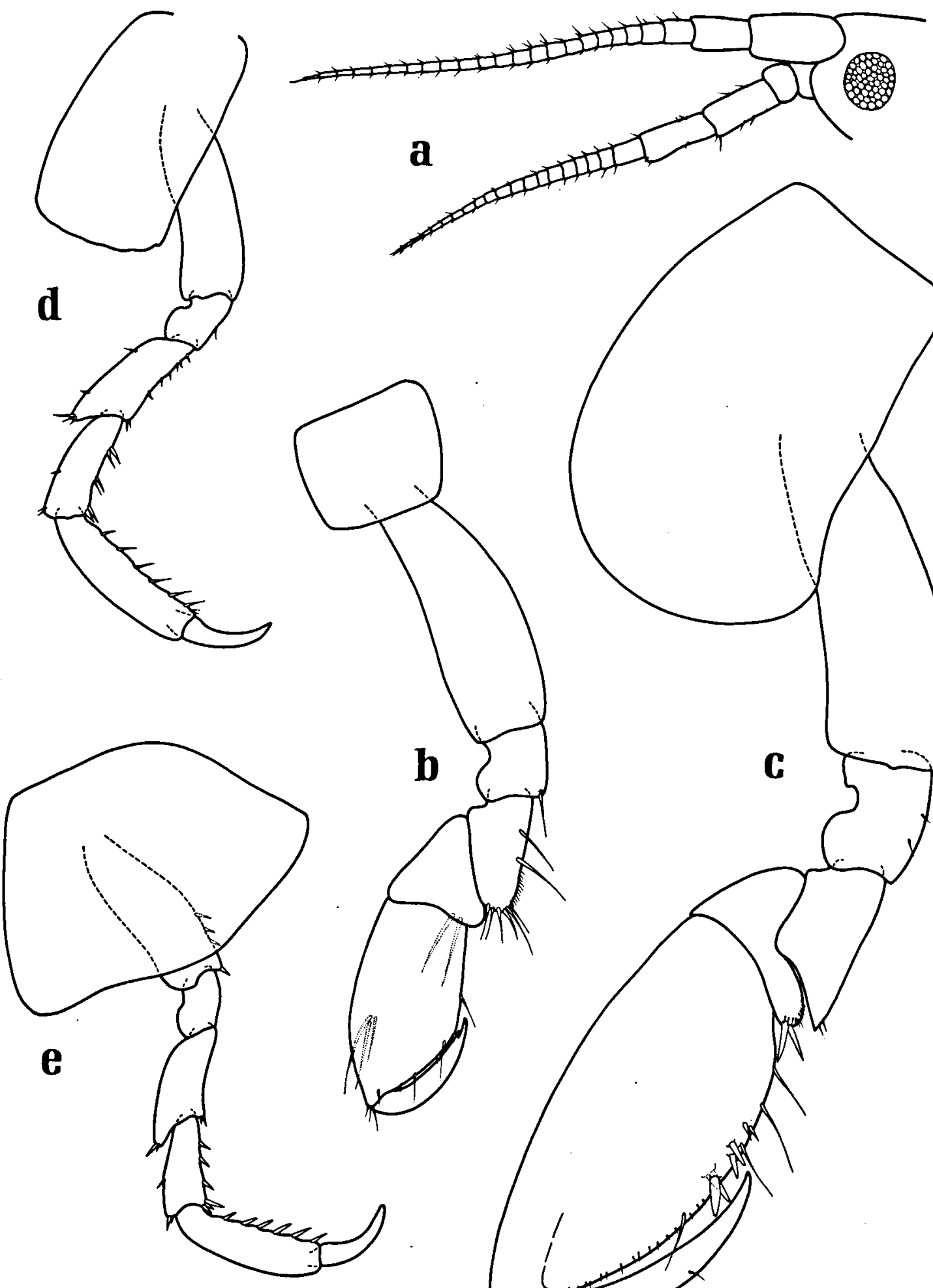

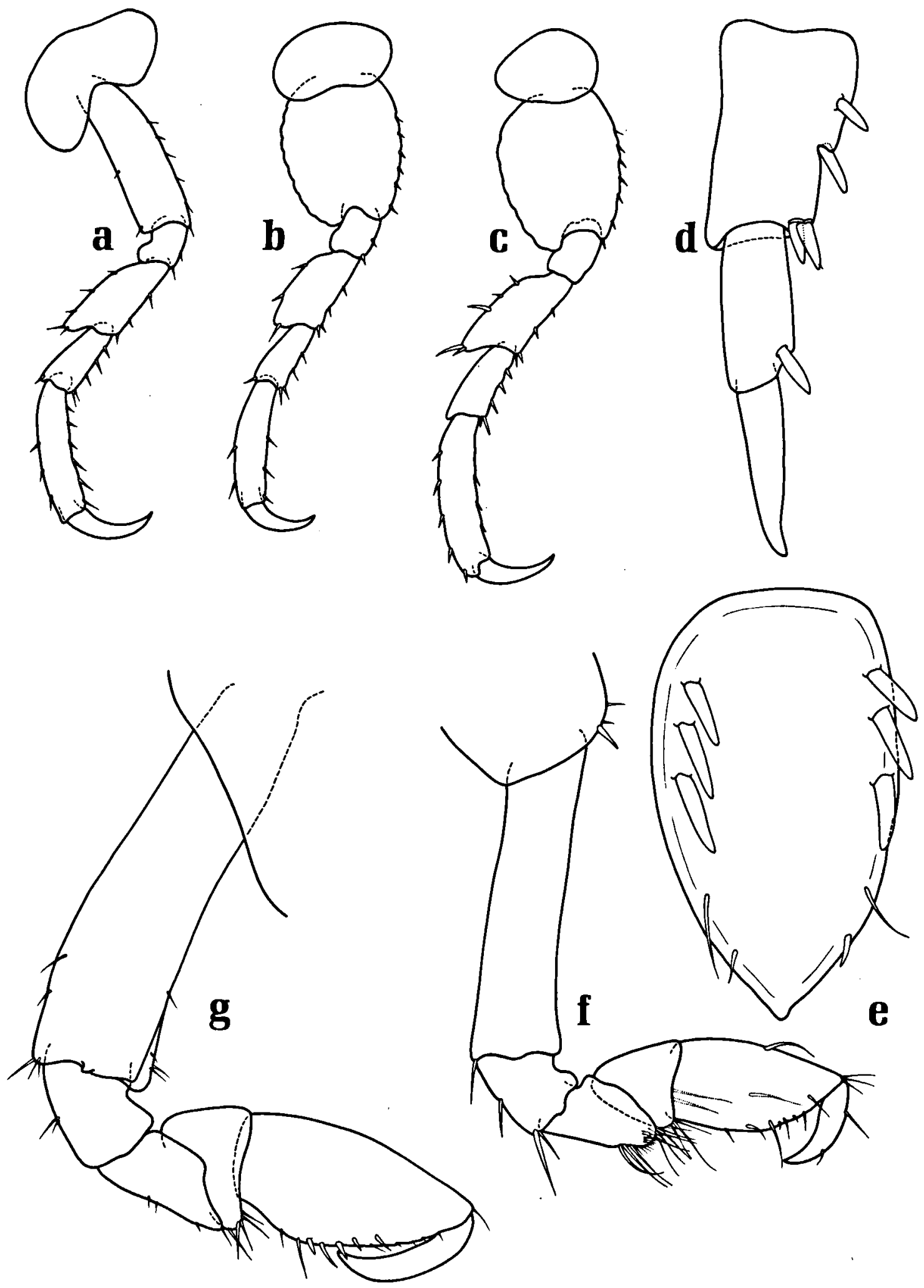

Abb. 2. Stenothoe tergestina (Nebeski, 1880). a, P5 §, १; b, P6 §, \&; c, P7 §, \&; d, U3 §, \&; ; Telson; f, Gnl q;g, Gn2 \&. 


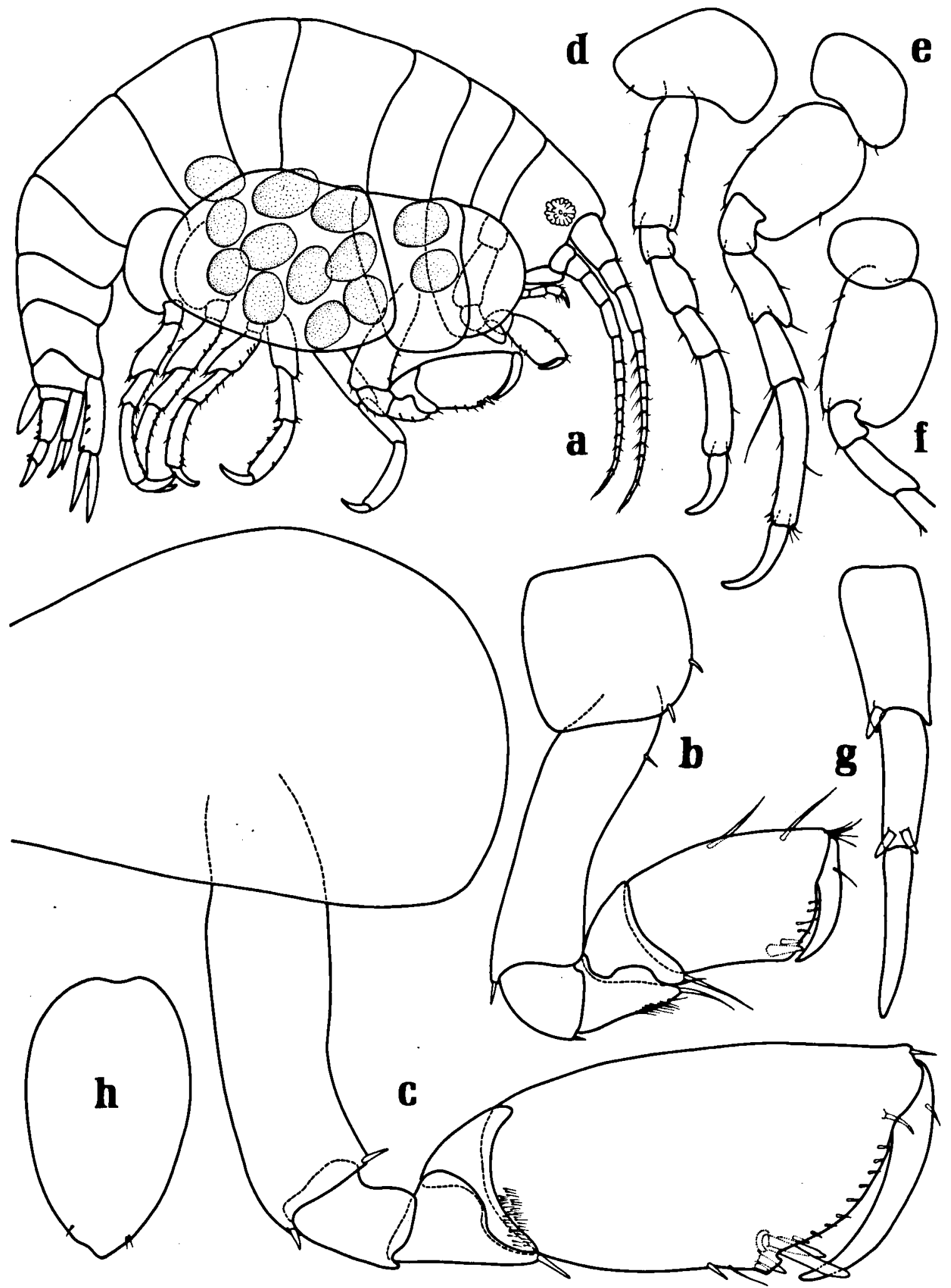

Abb. 3. Stenothoe monoculoides (Montagu, 1815). a, Habitus $\$$ ov. $3 \mathrm{~mm}$ aus dem Atlantik; Rest

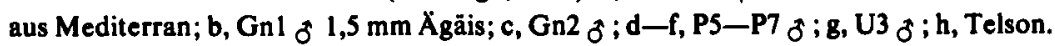




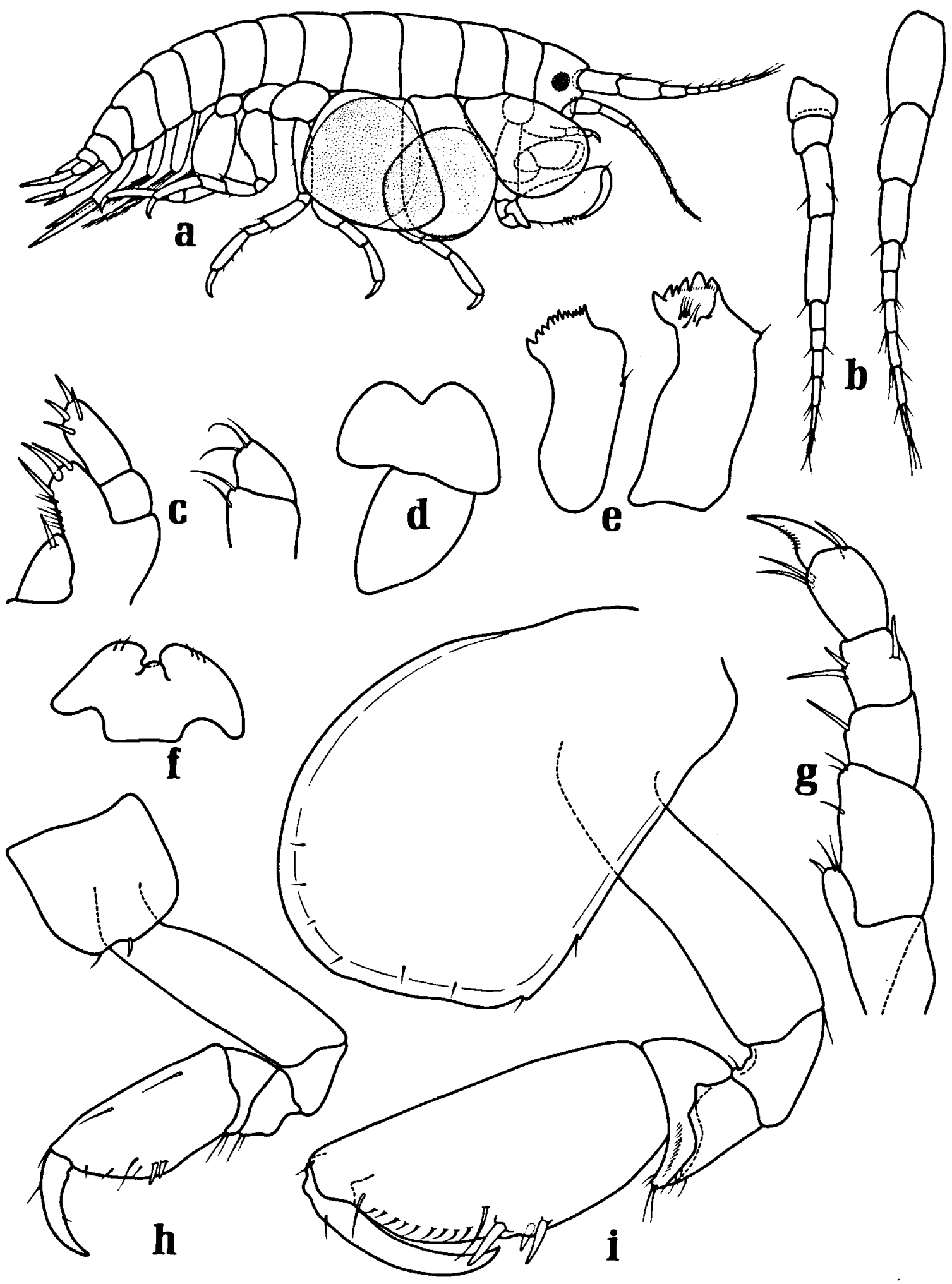

Abb. 4. Stenothoe elachista n. sp. a, Habitus 9 ov. $1,3 \mathrm{~mm}$ Livorno; b, Antennen o ; c, erste (links) und zweite (rechts) Maxille; d, Oberlippe; e, Mandibel von beiden Seiten; f, Unterlippe; g. Maxilliped; h, Gnl $\delta ; i$, Gn2 $\delta$. 


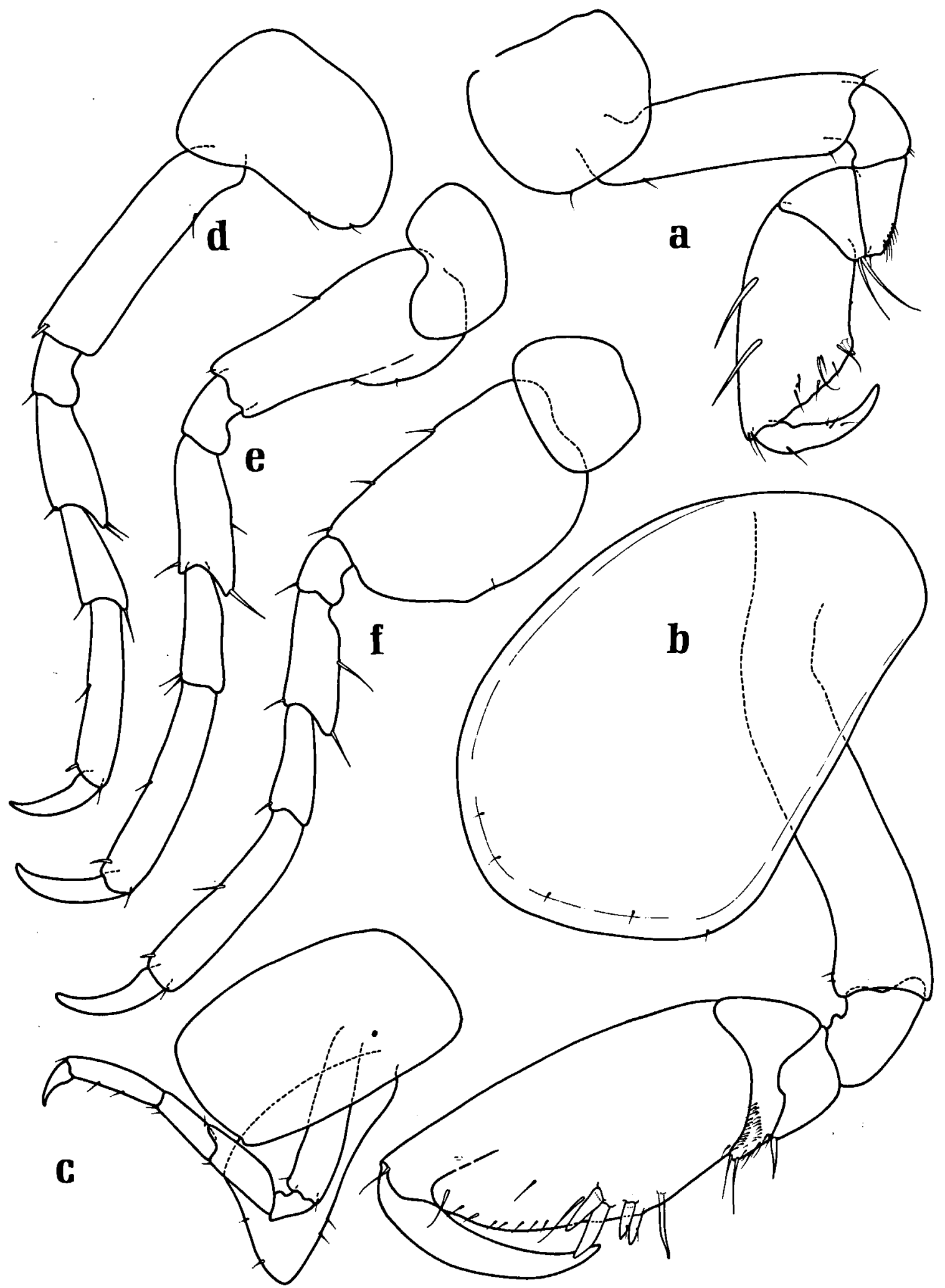

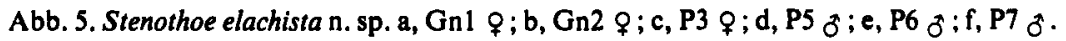




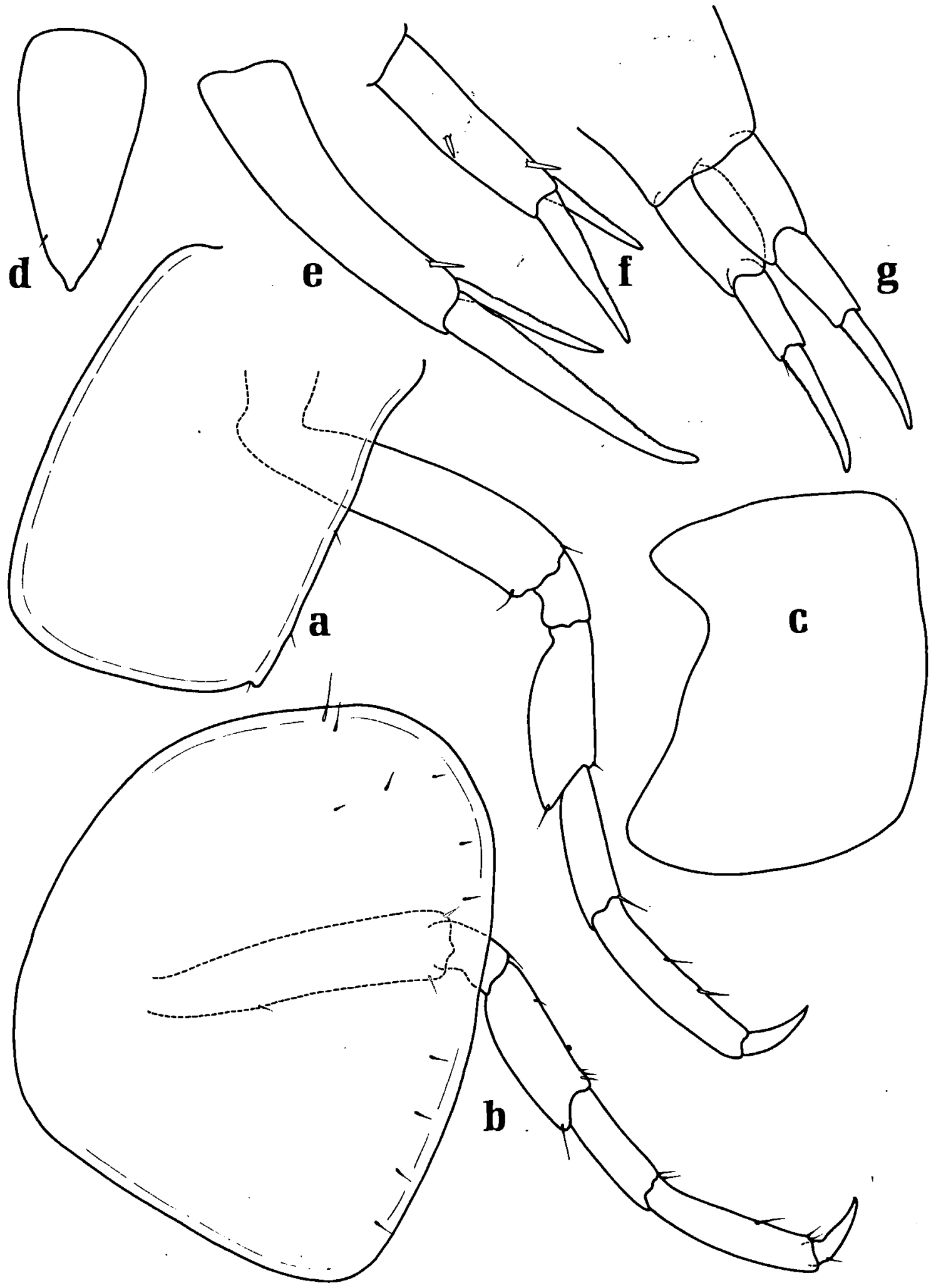

Abb. 6. Stenothoe elachista n. sp. a, P3 ठ ; b, P4 $\delta$; c, dritte Epimeralplatte $q ;$ d, Telson $\delta$; e-g, UI-U3 $\sigma$. 
O); $15 \mathrm{~m}$. Zehn Individuen von Livorno $\left(43^{\circ} 34^{\prime} 10^{\prime \prime} \mathrm{N} 10^{\circ} 13^{\prime}\right.$ 40"O); 3-4 m; alle 1972. Rund 60 Individuen aus 19 Proben Grob- und Feinsand von Ischia (Golf von Neapel, 1968) von 0,5-40 m Tiefe. Stärkstes Vorkommen: Maronti, Tiefe $0,5-2,5 \mathrm{~m}$, in Amphioxus-Sand.

Locus typicus: Livorno, erstgenannter Platz.

Holotypus: $1 \delta$, mikroskopisches Präparat (siehe Zeichnungen), deponiert am Museo Civico di Storia naturale, Verona (Italien).

Paratypen: etwa zur Hälfte der Sammlung des Zoölogisch Museum Amsterdam (Niederlande) einverleibt (Koll. Nr. ZMA Amph. 104. 767), der Rest beim Autor.

Schon Chevreux, 1911 (:196), bemerkt bei der Abhandlung seiner Stenothoe monoculoides, daß die typische Form im Mediterran wie Atlantik in Litoralalgen lebt und etwa $3 \mathrm{~mm}$ lang werden kann, daß er jedoch in zwei Stationen (die eine mit Sand und Posidonia bei Bône, $10 \mathrm{~m}$, die andere in der Năhe, Tiefe $12 \mathrm{~m}$ ) eine ,kleine Form" fand, deren Länge zwischen 1 und $1,3 \mathrm{~mm}$ lag, darunter auch eiertragende Weibchen. Er hielt sie erst für eine neue Art, doch brachte ein aufmerksames Studium der Morphologie keine Unterschiede zur typischen Litoral-bewohnenden St. monoculoides. Er gibt ferner auch zwei Lokalitäten aus dem Atlantik an (Croisic und BasseKikerikie, $18 \mathrm{~m}$ ), wo er die ,kleine Form” (dieselbe Art?) fand.

Allein die deutlich unterschiedliche Okologie sowie Biologie von St. monoculoides und der hier diskutierten Art sollten Ursache geben, an dem Vorhandensein ein und derselben Art zu zweifeln. Doch bestehen glücklicherweise auch konstante morphologische Unterschiede, die eine Abtrennung erleichtern.

Beschreibung. $\delta$ : Länge $1-1,5 \mathrm{~mm}$. Augen rund.

Erste Antenne geringfügig länger als zweite, etwa halb so lang wie der Körper. Flagellum 6gliedrig.

Zweite Antenne mit zartem Pedunculus, Flagellum ebenfalls 6-gliedrig.

Mundgliedmaßen: wie für das Genus charakteristisch.

Coxalplatten 2-4: im Verhältnis zur Höhe der Körpersegmente deutlich länger, sowie auffallend verbreitert.

Gnathopod 1: Propodus schwach, schlank, mehr als doppelt so lang wie breit, mit sanft verlaufender Palmarkante und schwachen Stacheln. Carpus und Merus posterodistal mit langen Borsten besetzt.
Gnathopod 2: Propodusform ähnlich schlank wie bei den ersten. Die ohne deutlichen Winkel verlaufende Palmarkante grenzen drei schwache Stacheln ab.

Peraeopoden 3-5: relativ schwach, mit schlanker Basis.

Peraeopod 6: auffallend langgezogene, schlanke Basis, immer mehr als doppelt so lang wie breit. Bei eben adulten Individuen beginnt eine proximale Ausbauchung deutlich in der Mitte der Basis, bei hyperadulten verläuft die BasisHinterkontur gleichmäßiger.

Peraeopod 7: Basisbreite größer als halbe Länge. Sonst wie vorige.

Epimeralplatten: ohne auffallende Merkmale.

Uropoden 1-2: bei Jungadulten sind die Äste stark ungleich, bei Hyperadulten ist der Unterschied gering.

Uropod 3: schlank, geringe bis ganz fehlende Bedornung.

Telson: größte Breite proximal; Länge zu Breite etwa $2: 1$. Distal mit deutlich ausgezogenem Endzipfel.

१: Ohne wesentliche Unterschiede zu oben. Wenige, sehr dotterreiche Eier.

Diskussion. -

Die Arten St. elachista und monoculoides unterscheiden sich vor allem durch: die Zahl der Eier der reifen Weibchen (bis max. 4 bei elachista, über 20 bei monoculoides), die Form der Basis von P6 (bei monoculoides ohne Unterschied zu P7; bei elachista schlanker, untere Hälfte der Basishinterkante parallel zur Vorderkante), das Telson (Breite zu Länge $1: 2$ bei elachista, breiter und mit bauchiger Kontur bei monoculoides).

Derivatio nominis. -

Das hervorstechendste Merkmal dieser Art ist ihre Kleinheit, daher hier als Artbezeichnung der griechische Ausdruck für ,winzig".

Stenothoe cavimana Chevreux, 1908.

Abb. 7-8.

Stenothoe cavimana Chevreux, 1908a: 1, Abb. 1-3; Chevreux \& Fage, 1925: 138-139, Abb. 138; Cecchini \& Parenzan, 1935: 177-178; Bellan-Santini \& Ledoyer, 1973: 925, 929.

Eine ähnlich kleine Art wie die vorige, die auch wegen des unbestachelten Telson und ähnlicher weiblicher Gnathopoden mit ihr verwechselt werden könnte. 

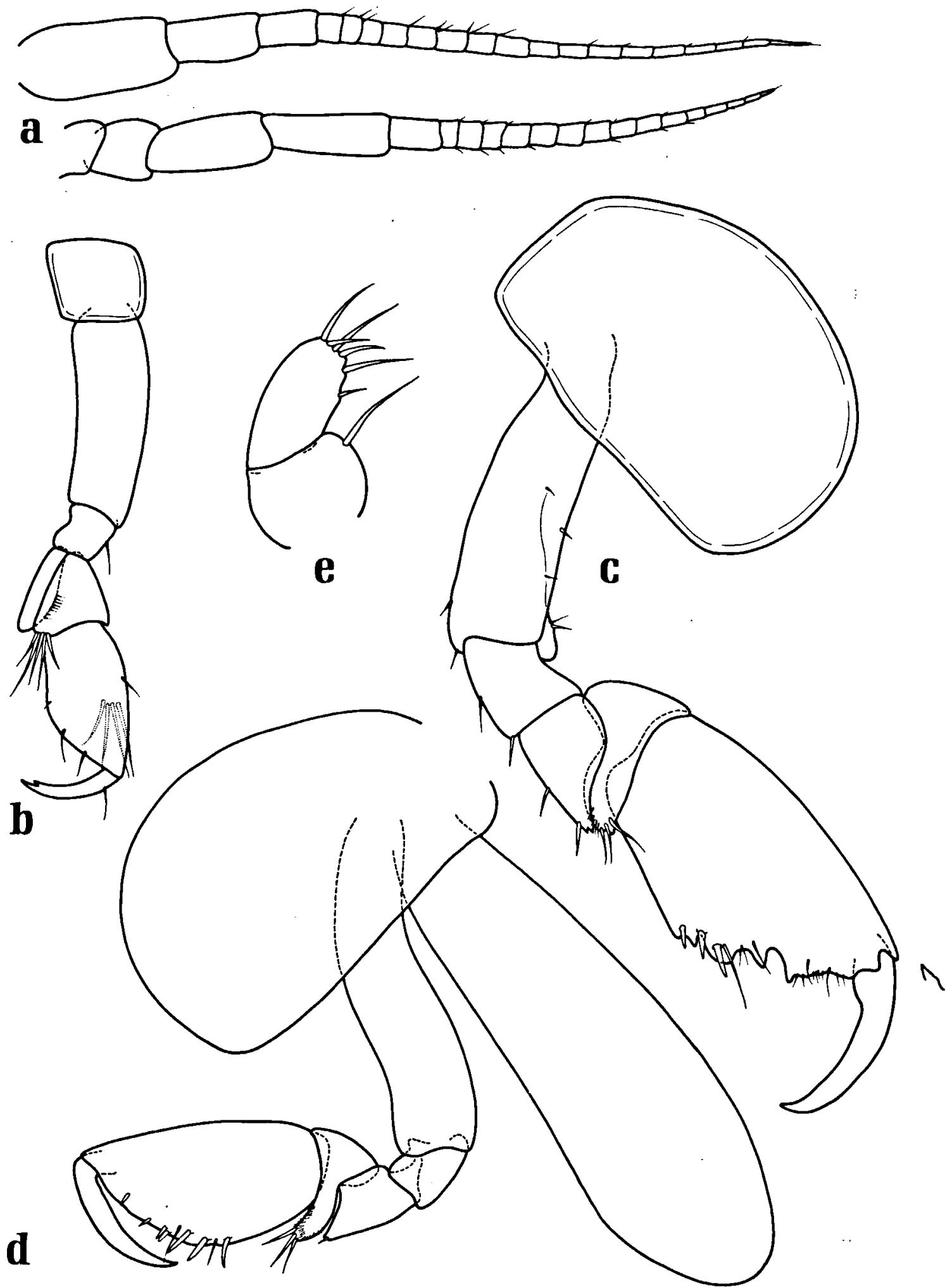

Abb. 7. Stenothoe cavimana Chevreux, 1908. a, Antennen o; b, Gn1 o, \&; c, Gn2 o; d, Gn2 \&; e, zweite Maxille. 


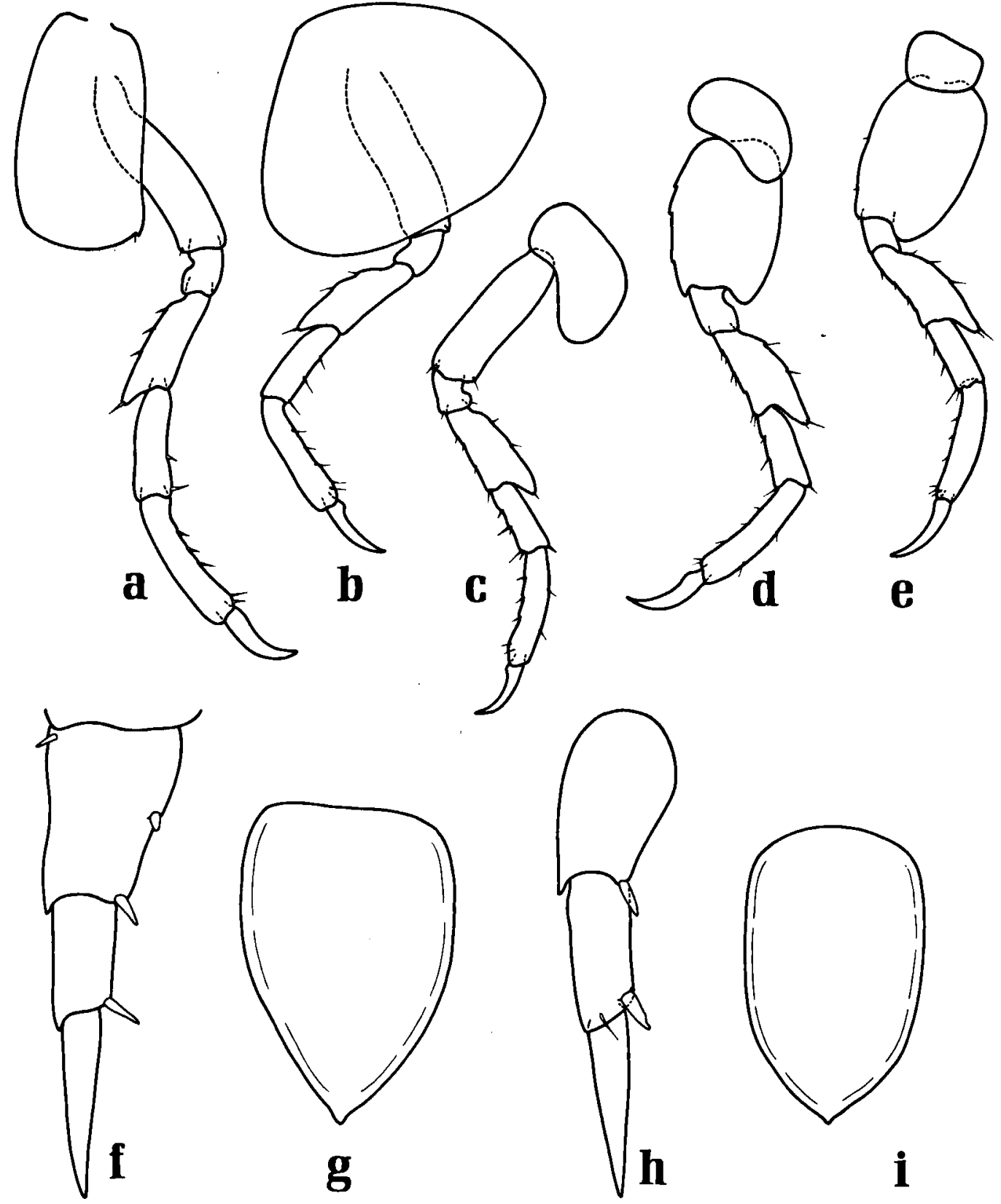

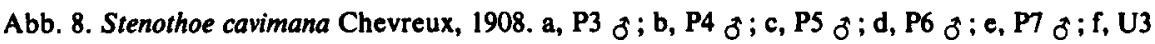
¿; , Telson $d$; h, U3 \&; i, Telson $\%$.

Doch ist die zweite Coxa bei St. elachista deutlich größer und breiter im Verhältnis zum Propodus, die Propodusbestachelung bei St. elachista stärker, schließlich sind die 6. und 7 . Peraeopoden bei St. cavimana subegal und die Meralglieder viel stärker ausladend als bei $S t$. elachista. Die ơ $\delta$ sind durch die markante Form der zweiten Gnathopoden von St. cavimana nicht zu verwechseln.

Uber die dritten Uropoden von St. cavimana ist zu sagen, daß der Pedunculus nicht nur ,ein wenig" kürzer als der Ast ist (Chevreux \& Fage, 1925: 138), sondern doch zumindest beim $q$ deutlich kürzer ist, sodaß diese Unterscheidungs- 
hilfe zu St. elachista wegfällt, obwohl Chevreux \& Fage dies beim Bestimmungsschlüssel verwenden.

Verbreitung. -

Atlantik: Saint-Jean-de-Luz. Mediterran: Sète, Marseille, Monaco, Napoli, Palermo (letzteres eigene Aufsammlungen, siehe Zeichnungen).

Stenothoe antennulariae Della Valle, 1893.

Abb. 9-10.

Stenothoe antennulariae Della Valle, 1893: 565-566, Taf. XXX Abb. 1-18; Schiecke, 1973: 15.

\section{Material. -}

Typusmaterial: etwa 80 Individuen vom Golf von Neapel aus Antennularia und Aglaophenia myriophyllum (Hydroiden); davon ca. $20 \%$ ov., $10 \delta \delta$, Rest Juvenile. Tiefe $50-80 \mathrm{~m}$.

Lectotypus: 1 adultes of (siehe Abb. 9-10) sowie die Seria syntypica im Museo Civico di Storia naturale von Verona deponiert, wo sich auch die übrige Della Valle-Sammlung befindet.

Da die Zeichnungen Della Valles zum Teil ungenau sind und er außerdem nur ein immatures $\delta$ beschrieb, werden hier nochmals komplette Abbildungen nach Della Valles Typusmaterial geboten.

\section{Diskussion. -}

Innerhalb der mediterranen Arten ist die vorliegende, $1,5 \mathrm{~mm}$ große Art vor allem durch die Form der ersten Gnathopoden beim $\delta$ wie auch o leicht erkennbar, da der Carpus praktisch gleiche Länge mit dem Propodus erreicht und etwa bis zur Hälfte eine fast parallele Vorderund Hinterkante zeigt, bevor der Merus die Hinterkante des Carpus verdeckt. Einzig St. bosphorana besitzt einen āhnlichen ersten Gnathopoden, wenn auch der Propodus dort etwas schlanker und der Carpus zu $2 / 3$ vom Merus überlappt ist; aber außer dieser Ahnlichkeit besteht kaum Gefahr, St. antennulariae in ihrer kleinen, robusten Gestalt mit den kurzen Antennen und relativ breiten Peraeopodenmeralgliedern mit der schlanken, langgliedrigen Schlammform St. bosphorana zu verwechseln.

Die zweiten Gnathopoden der Weibchen zeigen im Verlauf der sonst harmonisch-konvexen Palmarkante einen markanten Zahn, der sonst nur bei $S t$. valida- und $S t$. eduardi-Weibchen auftritt (siehe dort). Reife Weibchen von St. valida werden aber 5-6 mm groß, der Propodus der zweiten Gnathopoden ist schmal und langgezogen, vor allem aber ist der erste Gnathopod deutlich verschieden. Ähnlich steht es bei St. eduardi, wo auch der Propodus lang und schmal und der Zahn im Verhältnis recht klein ist, sowie der Carpus der ersten Gnathopoden ein verläßliches Unterscheidungsmerkmal bietet.

Die Palmarkante der zweiten Gnathopoden der Männchen muß noch hervorgehoben werden: Della Valle bildet ein juveniles Männchen $\mathrm{ab}$, obwohl in seiner Sammlung genügend adulte zur Verfügung waren. Erwachsene Männchen zeigen (siehe hier $\mathrm{Abb}$. 9c) eine viel stärker gezähnte und gekerbte Palma, die erst etwa im letzten Viertel der Propodushinterkante durch einen gedrungenen Dorn begrenzt wird.

\section{Verbreitung. -}

Stenothoe antennulariae wurde bisher ausschließlich im Golf von Neapel gefunden (Della Valle, 1893, Schiecke, 1973; in Hydroiden von 50-80 bzw. $55-70 \mathrm{~m}$ Tiefe).

\section{Bemerkung. -}

Sowinsky, 1898 (: 497-499), beschreibt eine "Stenothoe sp.", die möglicherweise St. antennulariae ist. Dafür sprechen die kurzen Antennen und die geschilderte sowie abgebildete Form der Gnathopoden, Peraeopoden und die zwei Stacheln am Telsonrand. Dagegen spricht einzig die Größe von $2,53 \mathrm{~mm}$, die wiederum eher an Juvenile von $S t$. bosphorana denken ließe (vgl. Sowinsky Taf. XIII Fig. 1-10 mit Abb, 9, 10 bzw. Abb. 23 der vorliegenden Arbeit).

Ich verlasse nun die Gruppe der ,kleinen Stenothoen" und komme zum zweiten Problemkomplex, den Arten Stenothoe dollfusi, St. gallensis sowie „St. cattai" (die erst seit 1973 aus der Synonymie mit St. gallensis wieder zur selbstāndigen Art erhoben wurde), deren zweite männliche Gnathopoden einander sehr ähneln, was wohl bisher Anlaß zu Verwechslungen gab.

Stenothoe dollfusi Chevreux, 1887.

Abb. 11-13.

Stenothoe dollfusi Chevreux, 1887: 327, Text-Abb. 8; Chevreux, 1891: 260, Abb. 6-10; Chevreux, 1900: 53, Taf. VIII Abb. 1; Stebbing, 1906: 196; Chevreux \& Fage, 1925: 135, Abb. 134 .

Diese Art läßt sich durch einen deutlichen 
BIJDRAGEN TOT DE DIERKUNDE, 46 (1) - 1976

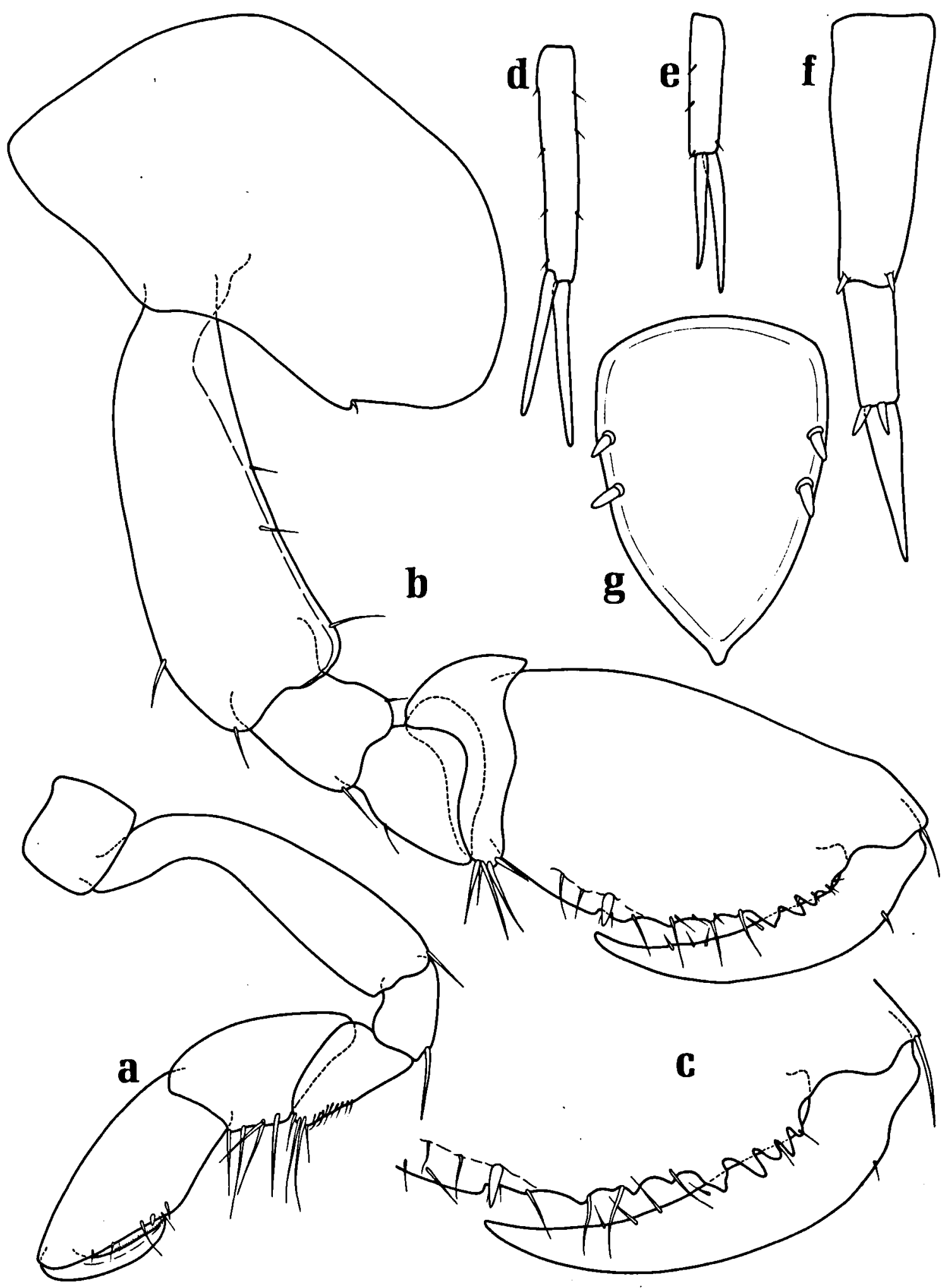

Abb. 9. Stenothoe antennulariae Della Valle, 1893. a, Gn1 $\delta, q ; b$, Gn2 adultes $\delta$; c, Palma von Gn2 ơ vergrößert; d-f, UI-U3 ơ ; g, Telson. 


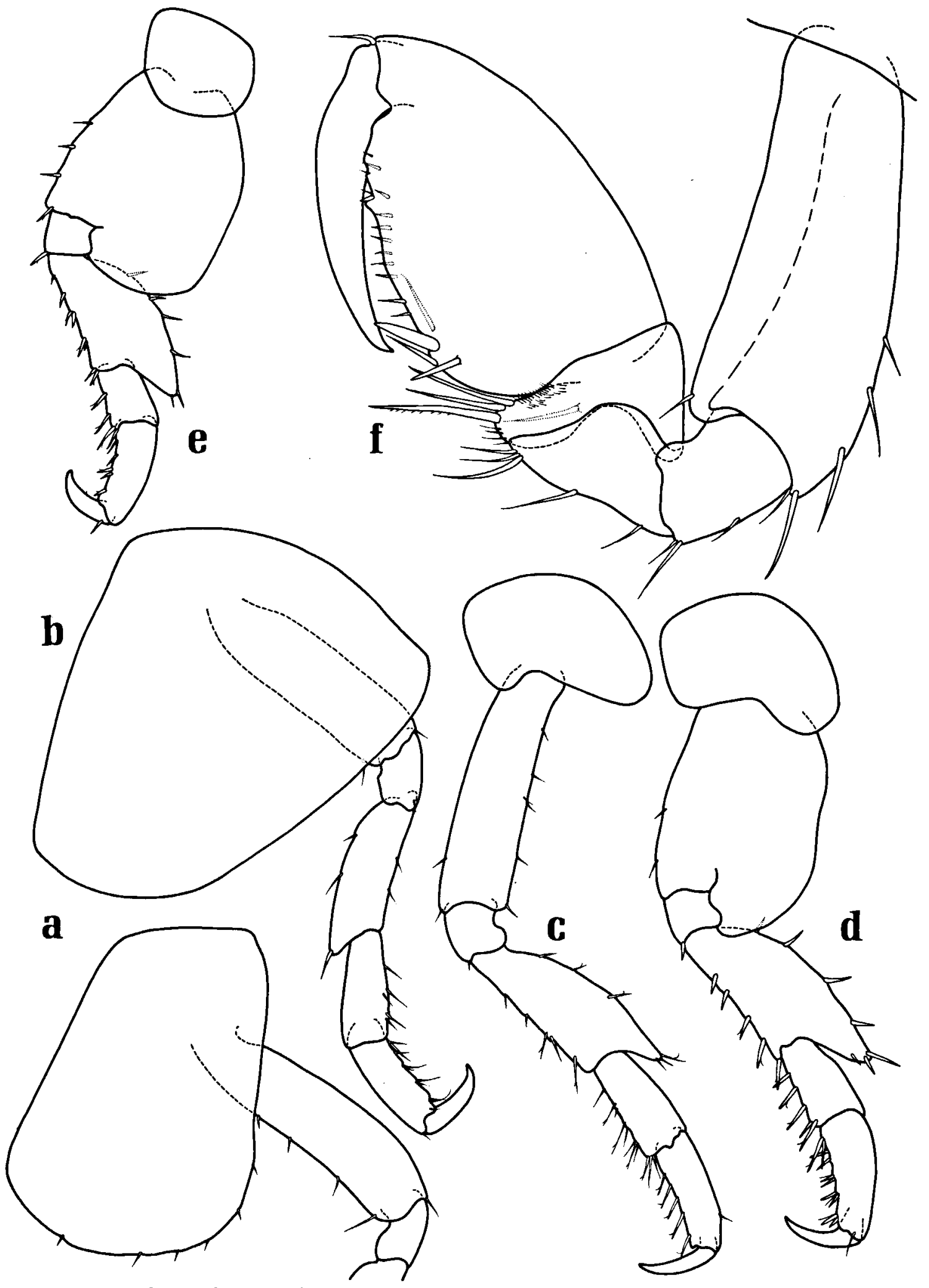

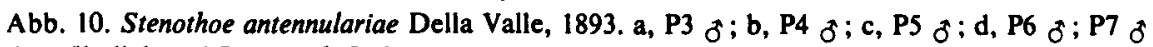
dazu ähnlich; e, P7 \& ov.; f, Gn2 \& ov. 


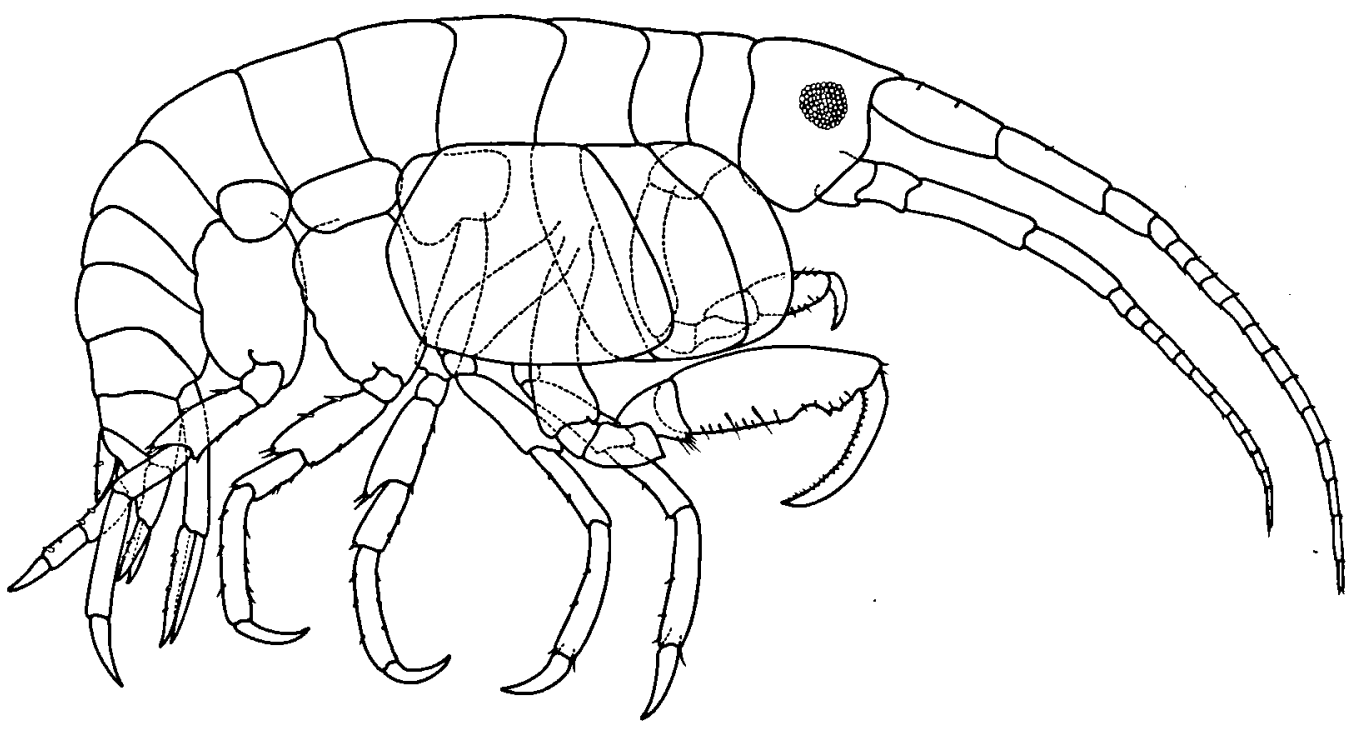

Abb. 11. Stenothoe dollfusi Chevreux, 1887. Habitus $q$ juvenil.

Einschnitt im zweiten weiblichen Gnathopoden, der auch in leichter Andeutung bei Juvenilen vorhanden ist (cf. Abb. 11, dann aber adultes $\%$, Abb. 12b), am leichtesten von den übrigen abtrennen. Sind ausnahmsweise überhaupt keine Weibchen vorhanden, dann können die ökologische Daten (siehe dort) noch Aufschluß bringen.

Die Zeichnungen wurden nach Material aus Rovinj und Pantelleria (eigene Aufsammlungen) angefertigt.

\section{Okologie. -}

St. dollfusi kam in meinen Sammlungen nie in den obersten Küstenmetern vor, sondern löste erst ab etwa 3-4 m Tiefe die Oberflächenart St. gallensis ab.

\section{Verbreitung. -}

Mediterran: Saint-Raphaël, Cannes, Napoli, Sizilien, Pantelleria, Rovinj; in Algen, 3-50 m. Azoren, 247-318 m.

Stenothoe gallensis Walker, 1904.

Abb. 14-16.

Probolium polyprion Catta, 1876 (non Costa, 1857!): 15, Taf. II Abb. 1.

Stenothoe gallensis Walker, 1904: 261, Taf. III Abb. 19; Stebbing, 1906: 725; Reid, 1951: 228-230, Abb. 27; Barnard, 1955: 3 (partim), Abb. 1; Ledoyer, 1973: 892, Abb. 10.

Stenothoe cattai Stebbing, 1906: 195.

Stenothoe crenulata Chevreux, 1907: 412-413; Chevreux, 1908c: 471-475, Abb. 1-3; Shoemaker, 1935: 236-237.
Von Stenothoe dollfusi läßt sich St. gallensis zweifelsfrei nur durch reife Weibchen trennen, wenn man von der deutlich verschiedenen Ökologie absieht.

Gefährlicher wird dagegen eine Verwechslung mit den weiblichen St. tergestina, worauf schon Barnard, 1955, hinwies, indem er die Art St. tergestina überhaupt für ungültig ansah, was keinesfalls zutrifft. Aber die zweiten $q$ Gnathopoden beider Arten ähneln sich sehr, die Okologie (siehe unten) ist praktisch dieselbe, die Robustheit der Peraeopoden ist etwa gleich. Hilfe kann hier nur die Größe bieten, die natürlich nicht verläßlich und nur relativ ist (St. gallensis ist eine größere, insgesamt robustere Art), vor allem aber das Verhältnis der Gnathopoden zueinander: bei St. gallensis ist der Propodus von $\mathrm{Gn} 1$ gleich oder kleiner als $2 / 3$ von Propodus Gn2. Außerdem trägt er am Palmarende zwei deutliche Stacheln. Bei St. tergestina ist der Propodus von $\mathrm{Gnl}$ größer oder gleich $3 / 4$ von Propodus Gn2, das Palmarende trägt keine Stacheln, nur Borsten.

Wichtig für die Unterscheidung der Männchen von St. gallensis gegenüber St. ,cattai" und $S t$. dollfusi ist das letzte Glied des dritten Uropoden. Reid, 1951, wie auch Barnard, 1955, bilden einen stark gerieften und tief gerillten Uropodendorn ab. Auch bei meinem Material ist eine leichte Krümmung des letzten Gliedes mit Riefung der Innenseite erkennbar, wogegen die anderen beiden Arten glatte Uropodenendglieder aufweisen. 


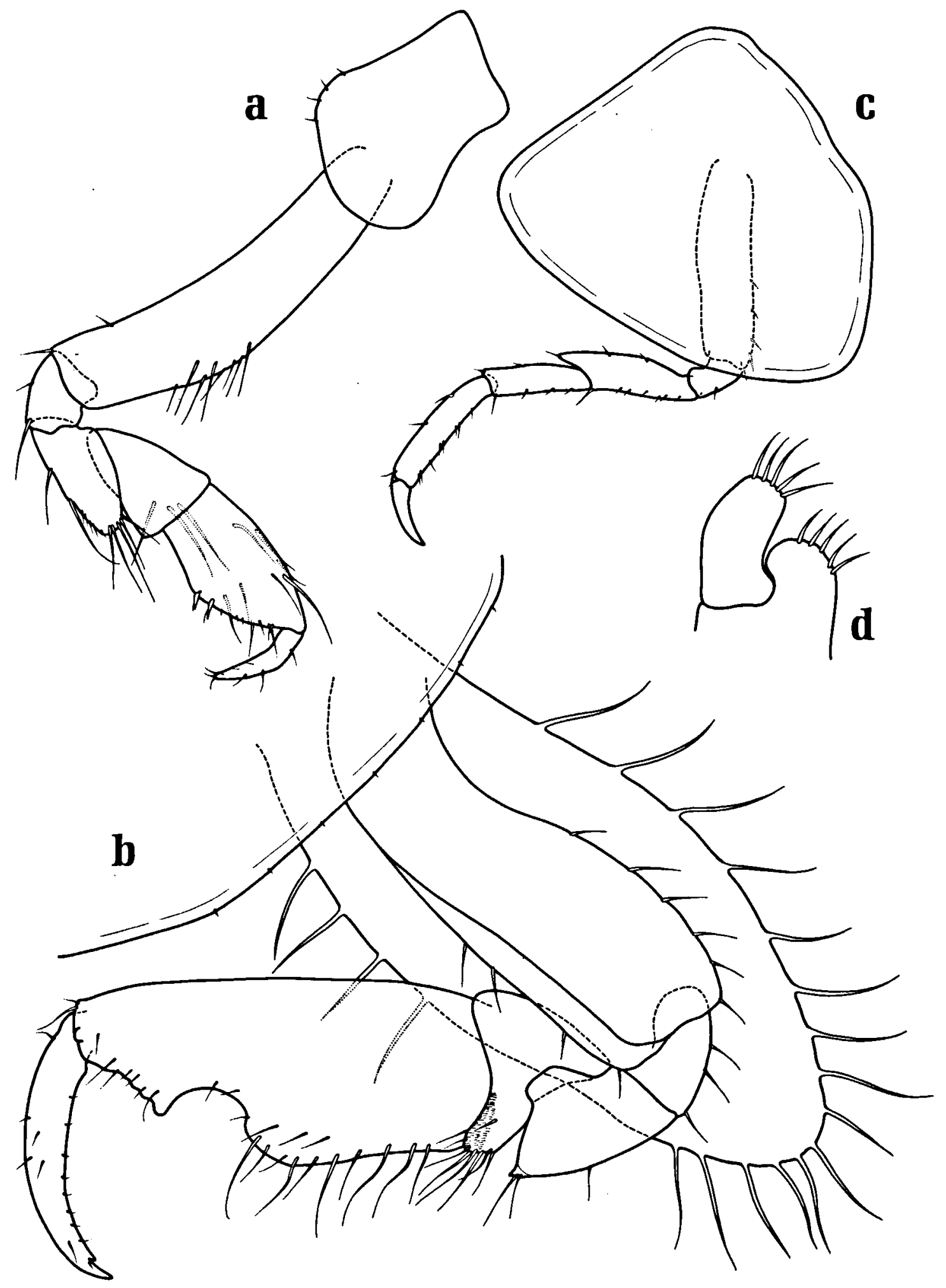

Abb. 12. Stenothoe dollfusi Chevreux, 1887. a, Gnl $\&$ ov.; b, Gn2 $९$ ov.; (beide in derselben Vergrößerung!); c, P4 o; d, zweite Maxille. 


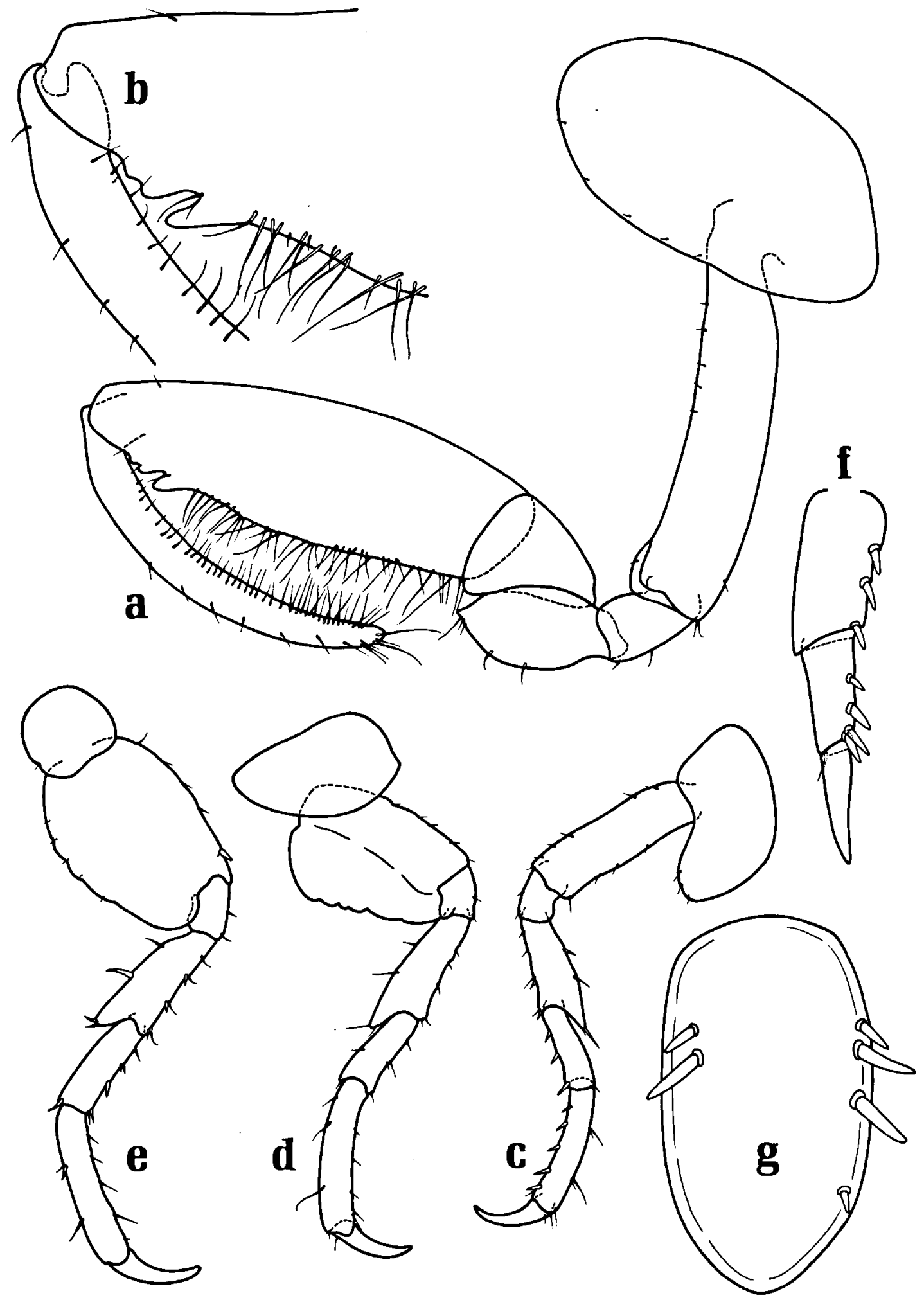

Abb. 13. Stenothoe dollfusi Chevreux, 1887, a, Gn2 o; b, distaler Teil der Palma und Dactylusansatz von $\mathrm{Gn} 2$ ơ vergrößert; $\mathrm{c}, \mathrm{P5}$ \%; d, P6 \&; e, P7 o ; f, U3 \&;g, Telson $\%$. 


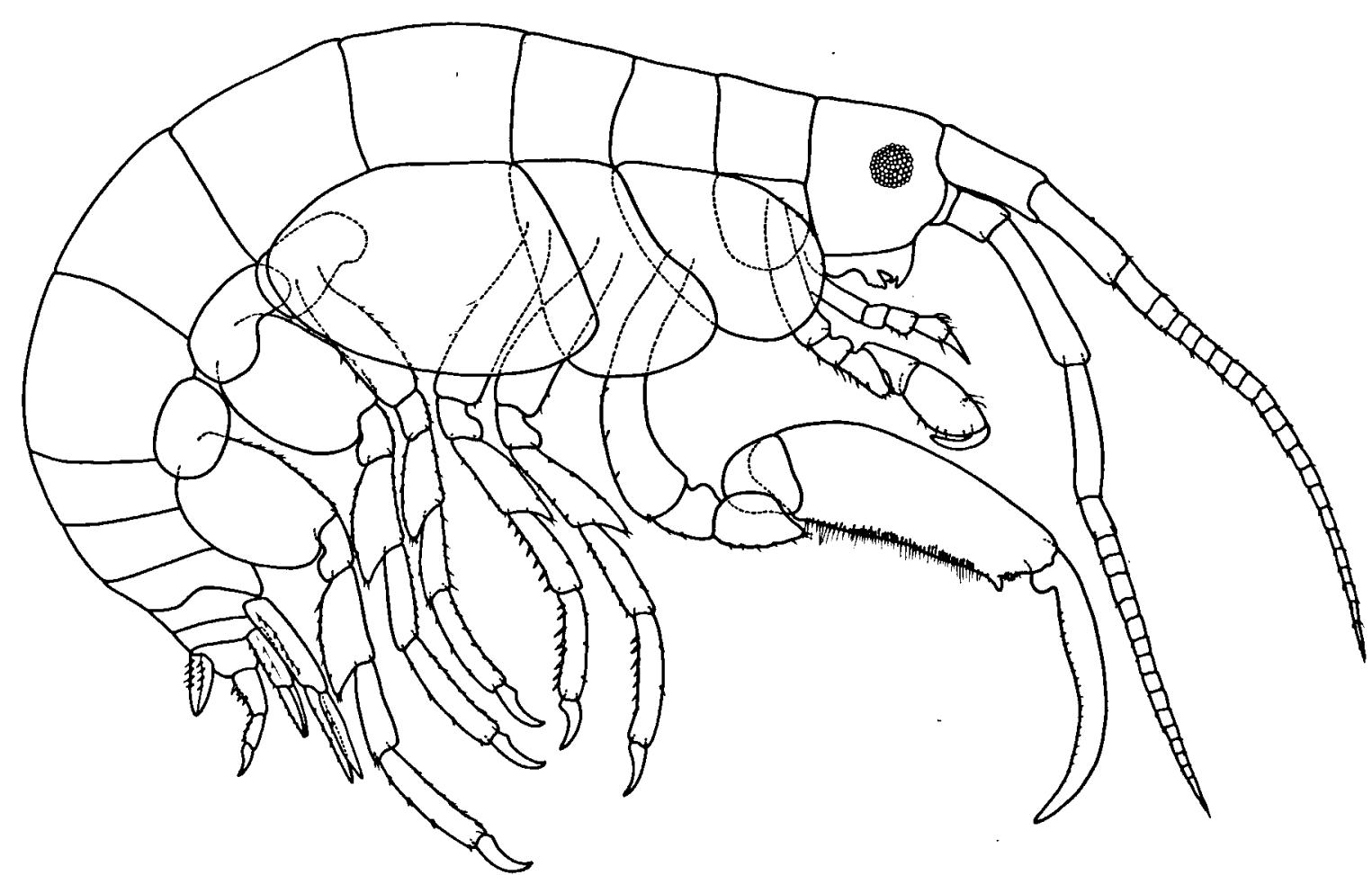

Abb. 14. Stenothoe gallensis Walker, 1904. Habitus adultes $\precsim$.

So stark wie Barnard, 1955, es abbildet, konnte ich jedoch dieses Merkmal in meinem Material nicht entdecken.

Die Zeichnungen wurden nach Individuen aus Catania angefertigt, die $\delta$ Gnathopoden auf Abb. 15 a, b \& d stammen aus Banyuls, auf Abb. $15 \mathrm{e}$ aus Pantelleria, und $\mathrm{Abb}$.'15f zeigt ein juveniles Männchen aus Catania. Die Uropoden 3 auf Abb. $161 \& \mathrm{~m}$ stammen ebenfalls aus Banyuls.

Okologie und Zoogeographie. -

In den Phytalproben aus der Nordadria wurde St. gallensis nie gefunden, wogegen in Sizilien St. tergestina noch etwas vertreten ist, hauptsächlich aber St. gallensis an ihre Stelle tritt. Letztere Art scheint demnach eine Form wärmerer Regionen zu sein.

St. gallensis bevorzugt wie St. tergestina (cf. Krapp-Schickel, 1969) gut durchlüftete Algen der obersten Küstenmeter, ich fand St. gallensis nur mehr selten unterhalb von $4 \mathrm{~m}$ Tiefe.

\section{Verbreitung. -}

Karib. Meer; Indopazifik: S-Afrika, Zanzibar, Dar-es-Salam, Rotes Meer (Ruffo, 1969), Sey- chellen Inseln, Ceylon, Gambier Inseln. Mediterran: Suez-Kanal (Monod, 1937), Catania (Sizilien), Pantelleria, Marseille, Banyuls. Trop. Atlantik.

Stenothoe eduardi n. sp. Abb. 17-18.

Stenothoe cattai (non Probolium polyprion Catta, 1876; non Stenothoe cattai Stebbing, 1906!); Chevreux \& Fage, 1925: 132-133, Abb. 131; Reid, 1951: 230-231, Abb. 28; Ledoyer, 1973: 889, 894, Abb. 10-11.

\section{Material. -}

Insgesamt über 100 Individuen aus 5 Proben aus dem Golf von Neapel 1970-1971: Punta S. Pancrazio (Ischia), Microcosmus, 20-25 m; ebenda, Algen und Sediment, $35 \mathrm{~m}$; ebenda, Schwãmme und Sediment, $30 \mathrm{~m}$; Punta S. Angelo (Ischia), 25-40 m; San Francesco (Wand), Schwämme, 6-12 m.

Locus typicus: Napoli.

Holotypus: $1 \delta$, mikroskopisches Präparat, deponiert am Museo Civico di Storia naturale von Verona.

Paratypen: zur Hälfte dem Zoōlogisch Museum Amsterdam einverleibt (Koll. Nr. ZMA Amph. 104.768 und 104.769), der Rest beim Autor.

Stenothoe cattai wurde von Srebbing, 1906 (: 195), beschrieben; es existiert kein Typusmaterial; als Locus typicus nennt er „Mediterranean”. Aus 


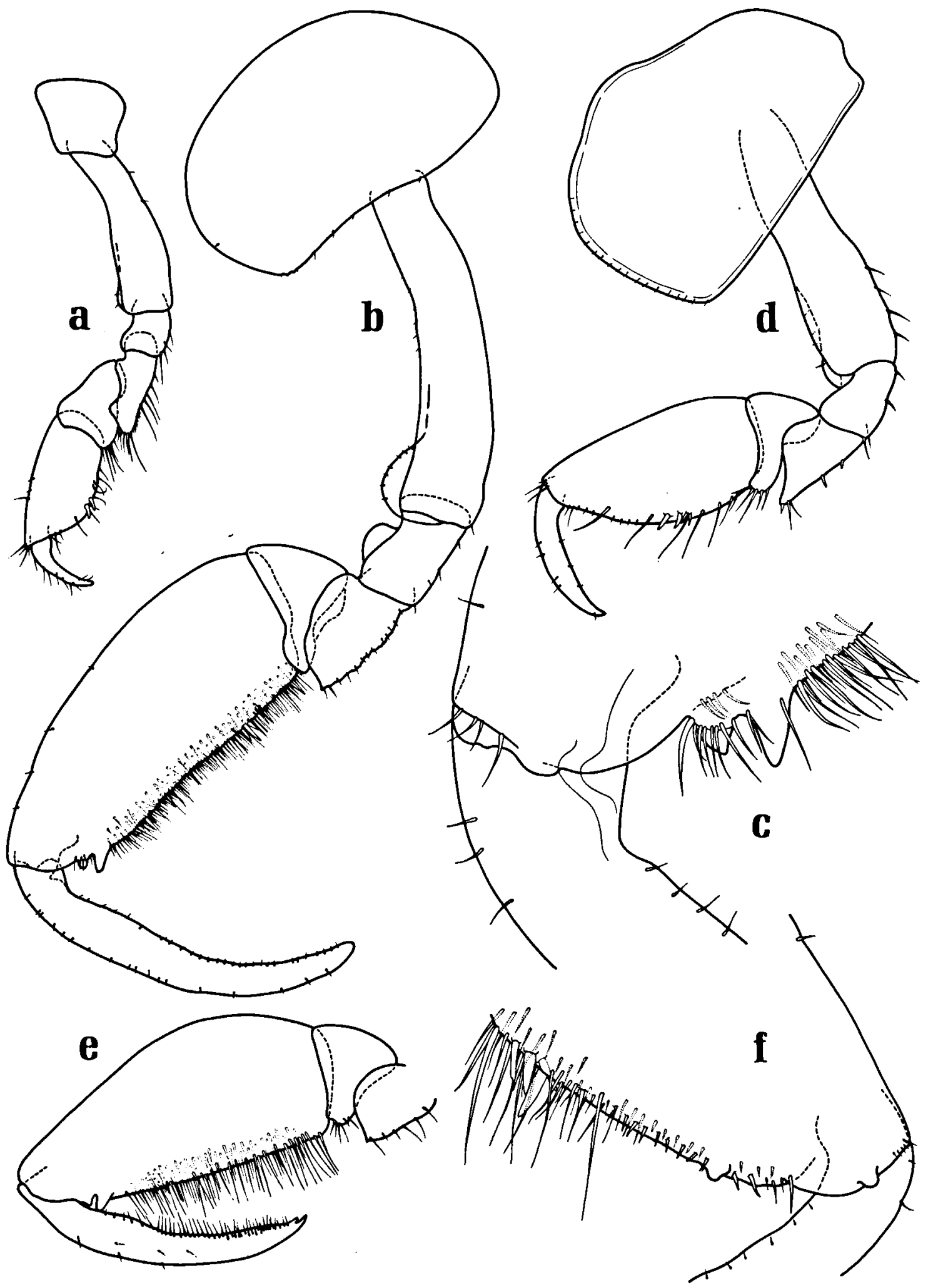

Abb. 15. Stenothoe gallensis Walker, 1904. a, Gnl $\delta$ aus Banyuls; b, Gn2 $\delta$ aus Banyuls; c, Detail aus b vergrößert; d, Gn2 $q$ aus Banyuls; e, Gn2 $\delta$ aus Pantelleria; $f, G n 2$ juveniles $\delta$ aus Catania. 


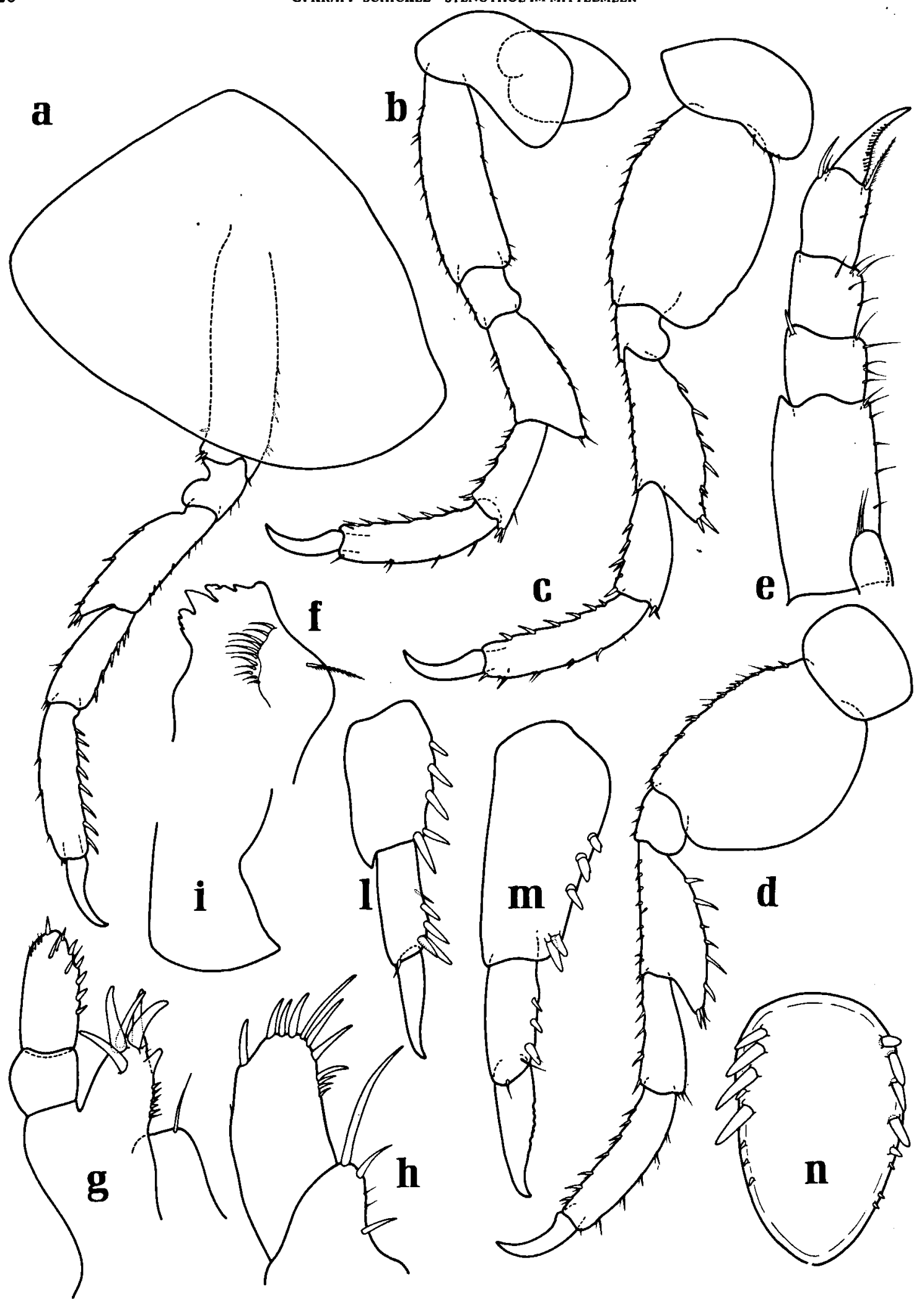

Abb. 16. Stenothoe gallensis Walker, 1904. a, P4 o ; b, P5 $\delta ; c$, P6 \&; d, P7 $\delta$ : e, Maxilliped; f, Mandibel; g, erste Maxille; h, zweite Maxille; i, dritte Epimeralplatte $\wp: 1$, U3 $\wp$ aus Banyuls; $\mathrm{m}, \mathrm{U3}$ of aus Banyuls; identisch mit of aus Catania; $\mathrm{n}$, Telson. 


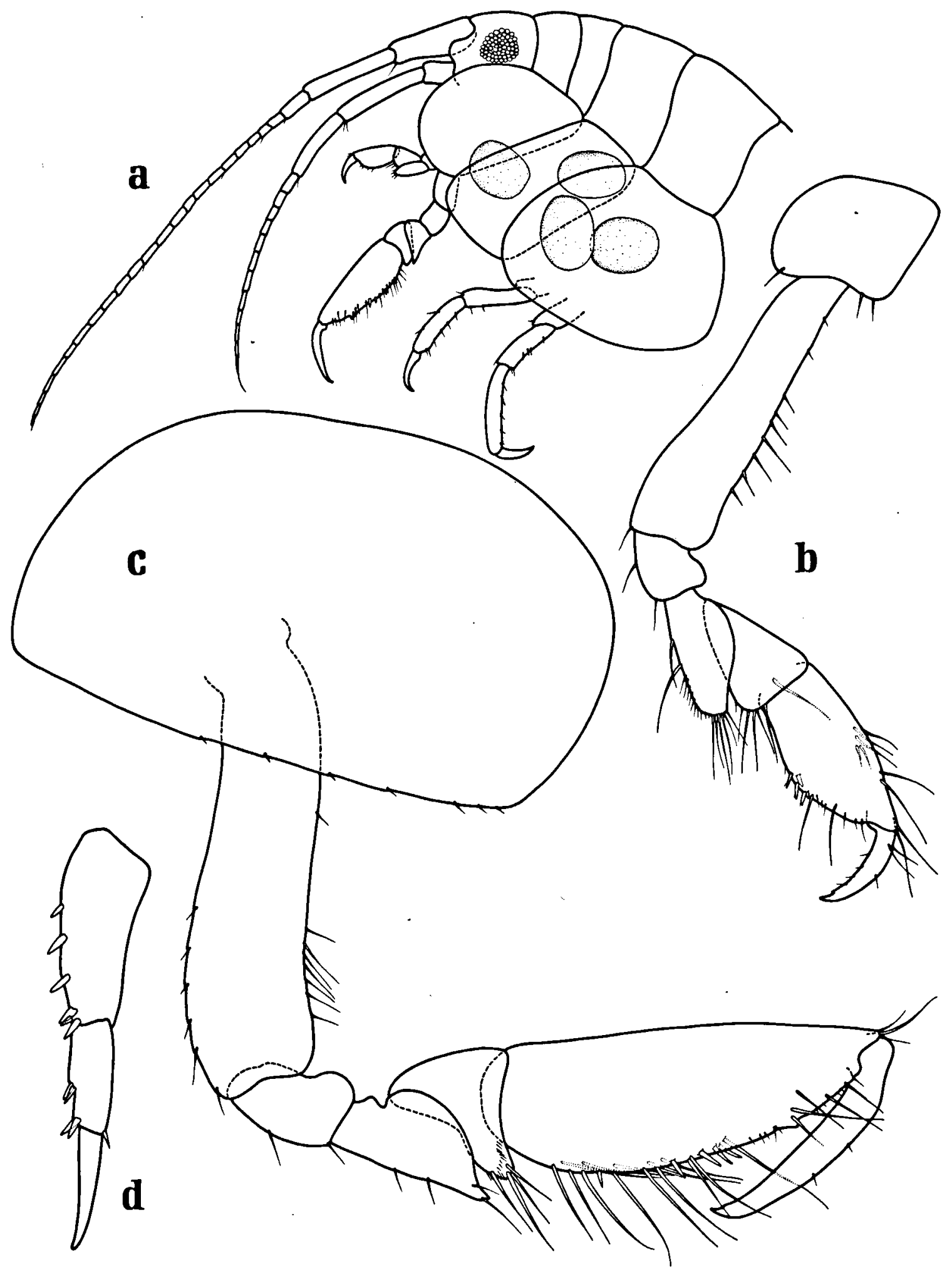

Abb. 17. Stenothoe eduardi n. sp., $\subsetneq$ ov. a, Kopf mit Antennen und Augenkontur, Vorderkörper; b, Gn1; c, Gn2; d, U3. 


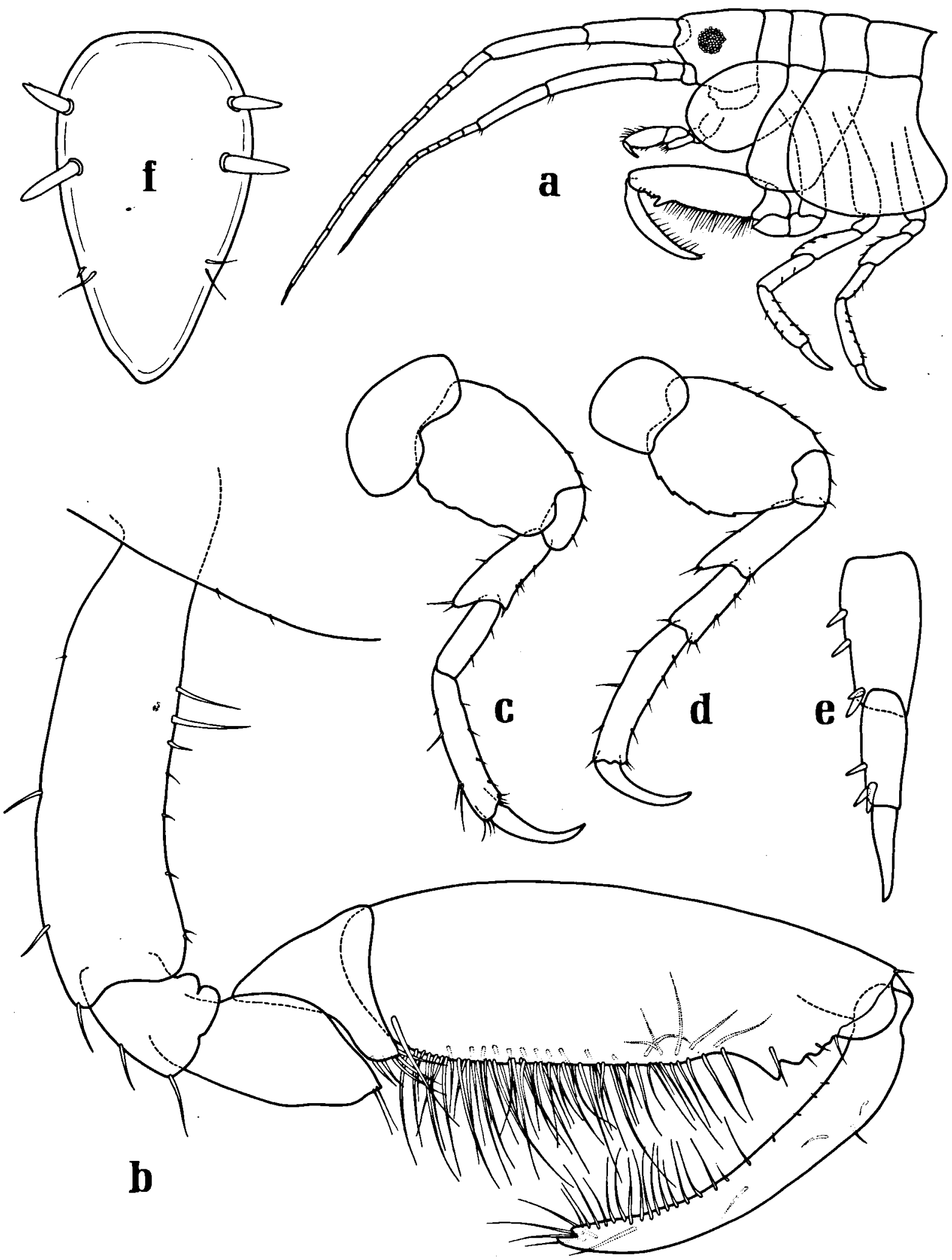

Abb. 18. Stenothoe eduardi n. sp., adultes $\delta$. a, Kopf mit Antennen und Augenkontur, Vorderkörper; b, Gn2; c, P6; d, P7; e, U3; f, Telson. 
seiner Synonymie und dem Artnamen darf gleichwohl geschlossen werden, daß dieser Name als Ersatz für Probolium polyprion Catta, 1876 (non Costa, 1857!) gedacht war. Aus Cattas Abbildungen wie auch Stebbings Beschreibung geht indessen deutlich hervor, daß es sich bei der vermeintlichen Art St. cattai um St. gallensis handeln muß. Catta erhielt seine Individuen vom Rumpf eines Schiffes, das aus Indien um das Kap der Guten Hoffnung nach Marseille gekommen war (vergleiche dazu Verbreitung von St. gallensis).

Bereits drei Autoren vor mir stellten fest, daß Stenothoe cattai sensu Chevreux \& Fage nicht synonym zu Stenothoe cattai Stebbing sei. Der erste war wohl Schellenberg, 1936 (: 10), bei seiner Abhandlung über St. gallensis, er wird zustimmend von Stephensen, 1949 (: 13), bei St. sivertseni zitiert. Schließlich bespricht Barnard, 1974 (: 123), bei St. miersi diese Diskrepanz und fordert, für das Tier von Chevreux \& Fage einen neuen Namen zu finden.

\section{Beschreibung. -}

\section{$\delta$ : Länge $4 \mathrm{~mm}$. Augen rund.}

Erste Antenne etwas lānger als zweite, etwa $2 / 3$ des Körpers. Flagellum 16-22 gliedrig.

Zweite Antenne noch etwas zarter, Flagellum $12-18$ gliedrig.

Coxalplatten 2-4: zunehmend länger und breiter werdend. Coxalplatte 4 gleich oder größer als $2+3$.

Gnathopod 1: Propodus oval, ohne markanten Winkel, doch mit kleinen Dornen am Palmarende. Meralglied erreicht das Distalende des Carpus.

Gnathopod 2: Propodus drei mal so lang wie der des Gnl. Ebenso wie Dactylus lang und dicht behaart. Propodushinterkante fast nicht gebaucht, beinahe parallel zu Vorderkante. Distales Drittel gerieft, gefolgt von einem tieferen Einschnitt und einem deutlich abgehobenen Zahn. Dactylus erreicht etwa $3 / 6$ der Propodushinterkante.

Peraeopoden 5-7: Meralglieder kaum erweitert sowie wenig verlängert. Dactyli etwa $3 / 5$ der Propoden erreichend.

Uropod 3: schlank, relativ dicht bedornt; Endglied immer deutlich kürzer als Pedunculus, leicht gekrümmt (in meinem Material ist das Endglied jedoch nie so kurz wie Chevreux \& Fage, 1925, es abbilden).
Telson: mit $2-3$ randlichen Dornen jederseits sowie einem Borstenpaar. Ohne ausgezogene Endzipfel.

\section{O: Bis zu 20 und mehr Eier.}

Gnathopod 2: Propodus etwa doppelt so lang wie der des Gnl. Am Ende des distalen Drittels ein stumpfer, zahnartiger Vorsprung (sehr wichtiges Merkmal für die Artentrennung!). Restliche Propodushinterkante glatt, mit langen Borsten besetzt. Dactylus erreicht etwas mehr als die Hälfte der Propodushinterkante.

\section{Diskussion. -}

Wie Ledoyer, 1973, hervorhebt, ist diese Art weniger bedornt als St. gallensis, was sich nicht nur in den letzten Uropoden, sondern ebenso deutlich am Telson und an den Peraeopoden ablesen läßt.

Darūber hinaus sind die Peraeopoden tatsāchlich, wie Ledoyer, 1973, nur durch eine Skizze andeutet, bei St. gallensis robuster, das Meralglied hebt sich viel deutlicher ab, während $S t$. eduardi relativ längere Dactyli besitzt, spärlich bestachelt ist und ein schlankes Meralglied aufweist.

Der männliche zweite Gnathopod ist bei St. gallensis viel dichter und auf größerer Fläche, aber mit kürzeren Haaren besetzt, während $S t$. eduardi lange Haare auf Dactylus und Propodus besitzt, die aber weiter voneinander entfernt stehen.

Okologie. -

Die Tiere traten in meiner Sammlung ausschlie Blich in Proben auf, die aus Schwämmen oder Aszidien (Innenraum wie Aufwuchs) gewonnen wurden, während dort weder St. gallensis noch St. dollfusi zu finden waren.

Verbreitung. -

Atlantik: Roscoff (Saccorhiza-Rhizome), trop. WAfrika. Mediterran: Marseille (Schiffsaufwuchs), Monaco, 10-30 m; Napoli 6-40 m (aus Schwäm. men und Aszidien).

Derivatio nominis. -

$\mathrm{Da}$ in den Diskussionen immer wieder die Rede von der ,Art Chevreuxs" im Gegensatz zur ,Art Stebbings" war, lag es nahe, bei der Benennung der Art Édouard Chevreux zu gedenken.

Ubrig sind nun noch jene Arten, die kaum mit 


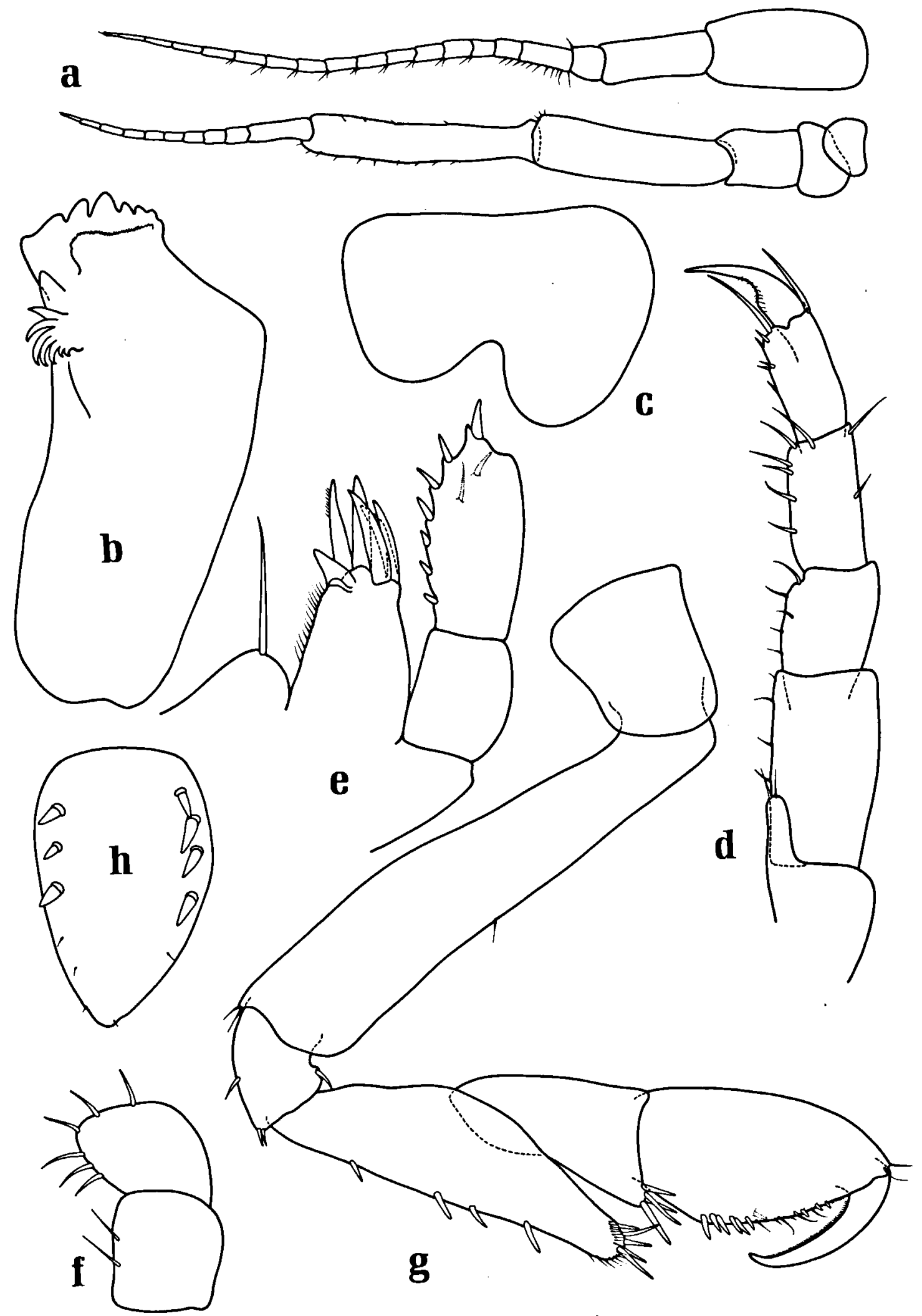

Abb. 19. Stenothoe valida Dana, 1853, o . a, Antennen; b, Mandibel; c, Oberlippe; d, Maxilliped; $e$, erste Maxille; f, zweite Maxille; g, Gnl; h, Telson. 


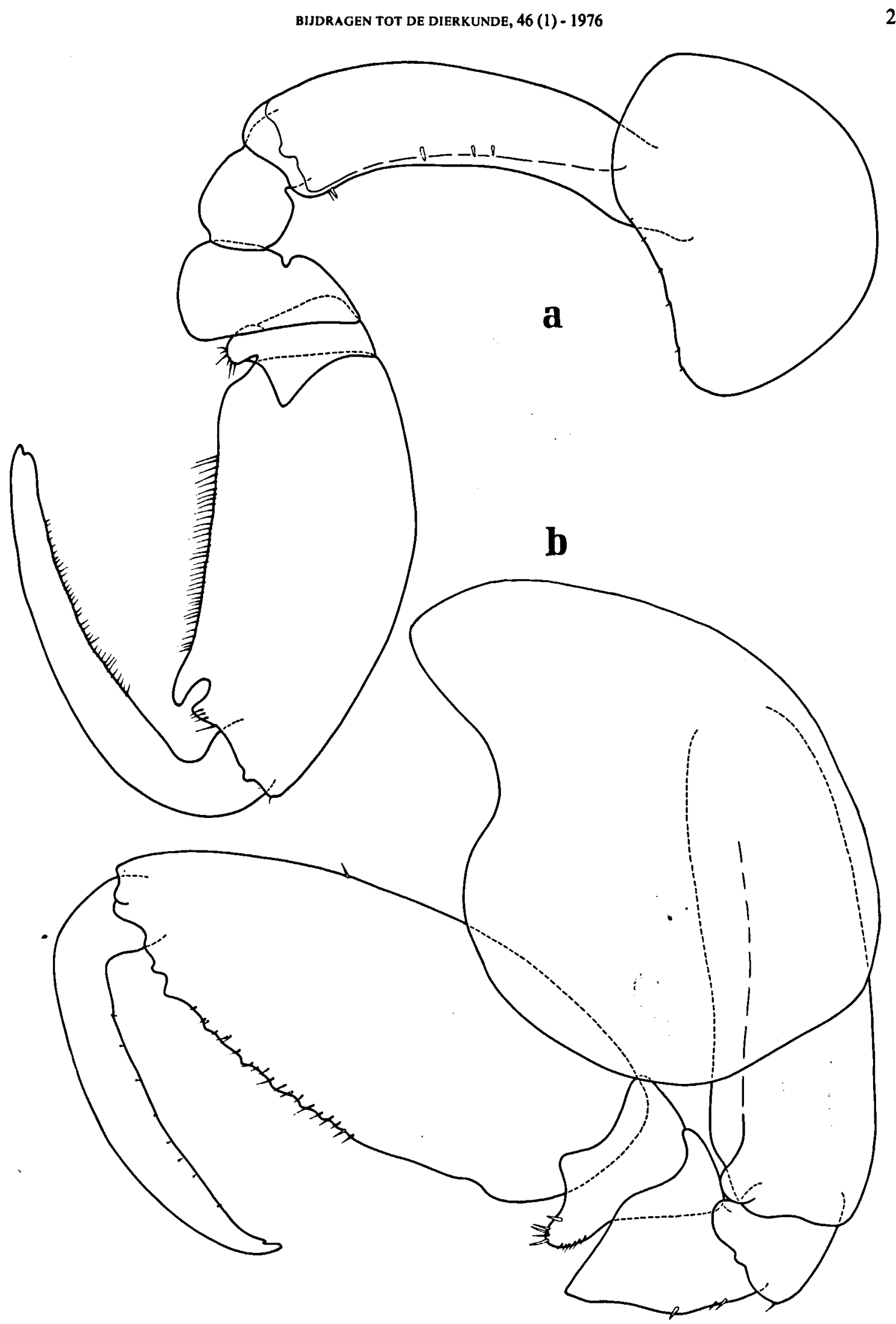

Abb. 20. Stenothoe valida Dana, 1853. a, Gn2 o ; b, Gn2 $\&$. 


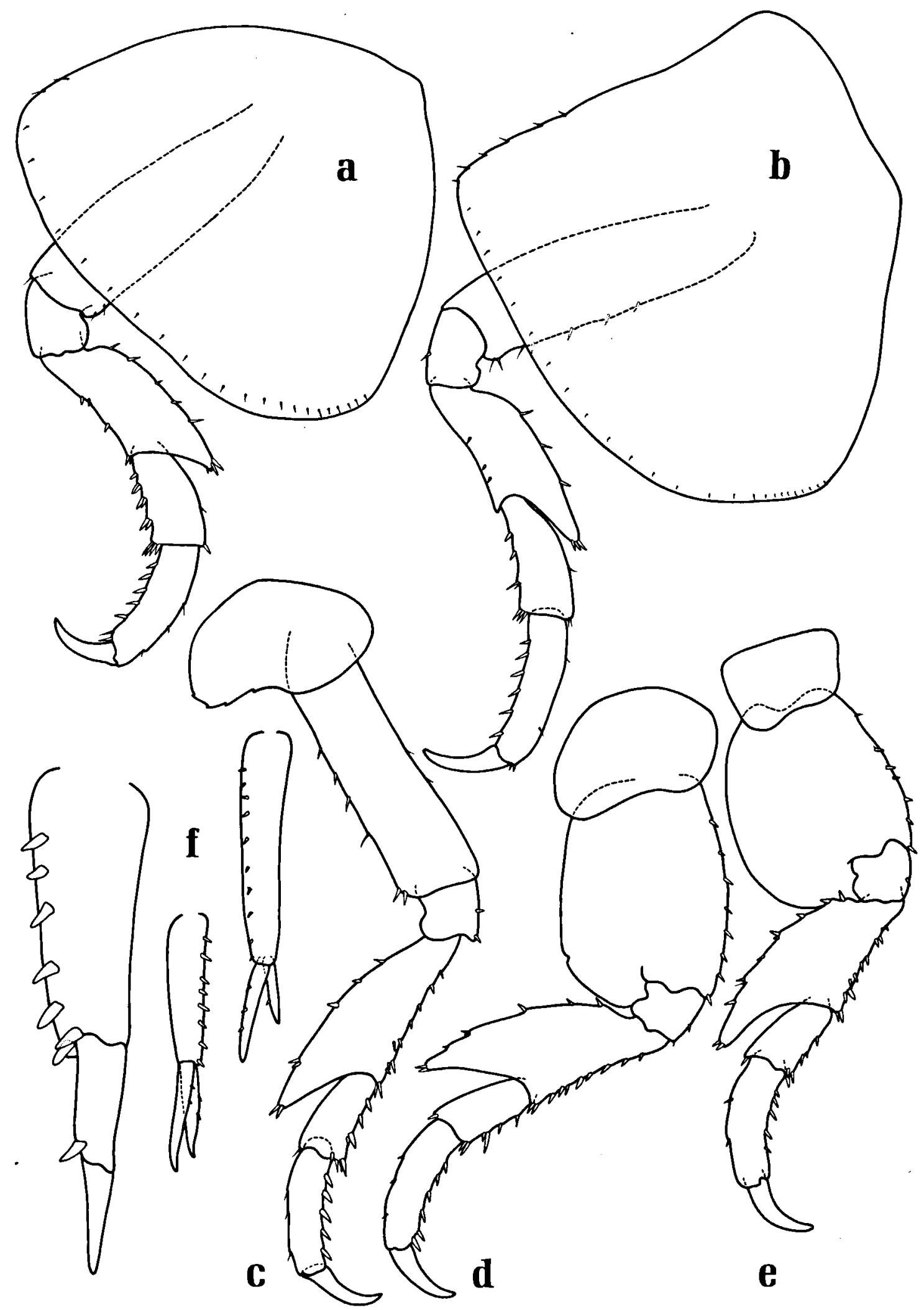

Abb. 21. Stenothoe valida Dana, 1853, § . a, P3; b, P4; c-e, P5-P7; f, U1-U3 von rechts nach links. 


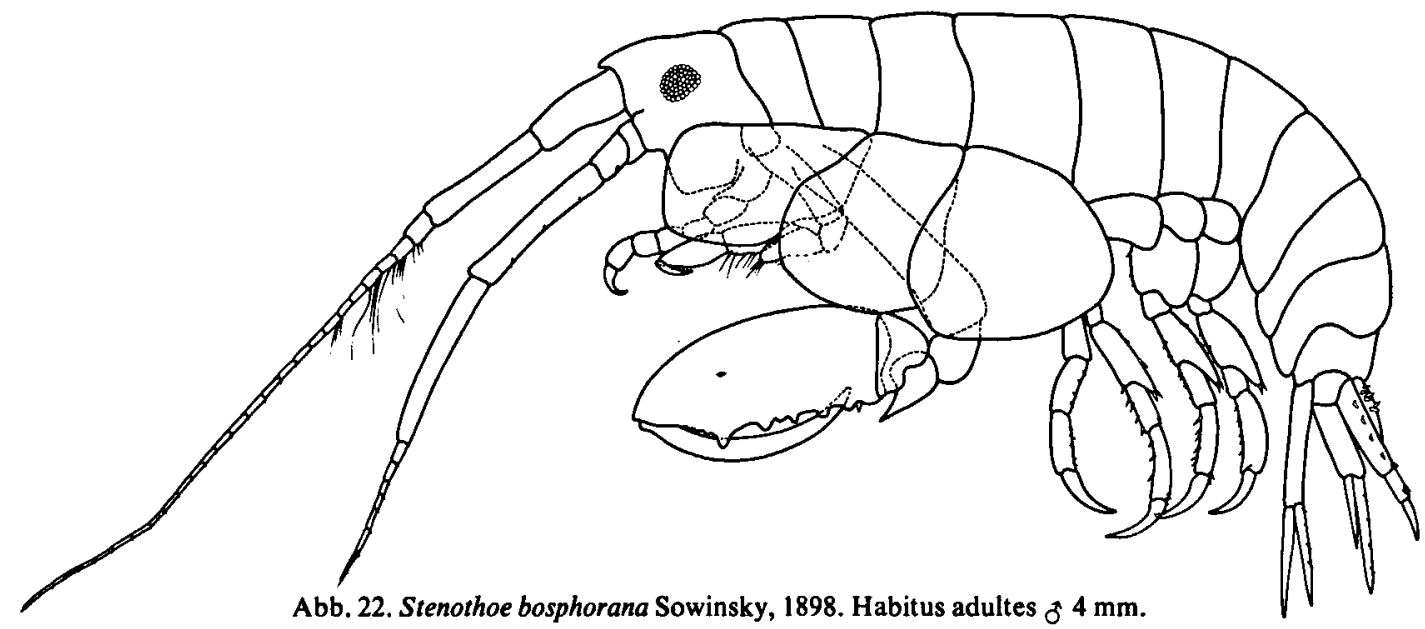

anderen verwechselt werden können: Stenothoe valida, St. „dactylipotens" und St. marina.

Stenothoe valida Dana, 1853.

Abb. 19-21.

Probolium polyprion Costa, 1857: 173.

Probolium megacheles Heller, 1866: 13, Taf. II Abb. 1-2.

Stenothoe assimilis Chevreux, 1908a: 4, Abb. 4-6.

Stenothoe valida; Chevreux, 1913: 2; Chevreux \& Fage, 1925: 137-138, Abb. 137.

Wie Stenothoe eduardi und St. antennulariae be. sitzt diese Art beim zweiten weiblichen Gnathopoden einen deutlichen Zahn am Distalende der Palmarkante, doch ist $S t$. valida durch die Form der Peraeopodenmeralglieder, vor allem beim letzten Peraeopodenpaar, sowie auch durch die etwas konkave Hinterseite der zweiten Coxalplatte sehr deutlich von allen übrigen zu trennen.

\section{Okologie. -}

Die mir vorliegenden Individuen stammen aus der Lagune von Venedig, wo ich sie aus Schwämmen und Aszidien geringer Tiefe (bis ca. $5 \mathrm{~m}$ ) gewann, die ihrerseits Bojen und „Bricole”, jene Holzpfähle zur Mytilus-Zucht, besiedelten.

Die Zeichnungen sind nach diesen Serien angefertigt.

Verbreitung. -

Diese Art ist typisch für "fouling portuale". Atlantik: Saint-Jean-de-Luz (Schwämme). Mediterran: Monaco, Lagune von Venedig. Bermuda Inseln, Brasilien, Peru, Neu-Seeland, Australien.
Stenothoe bosphorana Sowinsky, 1898.

Abb. 22-25.

Stenothoe bosphorana Sowinsky, 1898: 493-497, Taf. XI Abb 23-25, Taf. XIl Abb. 9-19.

Stenothoe dactylipotens Chevreux, 1908b: 4, Abb. 2; Chevreux \& Fage, 1925: 135-136, Abb. 135.

Stenothoe dentimana Chevreux, 1911: 199-201, Text-Abb. 8, Taf. XII Abb. 13-25.

Locus typicus: St. 37 (1893): Kudé, Bosporus, Tiefenstrōmung, $35 \mathrm{~m}$.

Typusexemplare: $2 \delta \delta, 4 q q$. Wo die Belege zu finden sind, ist mir nicht bekannt.

Lange zweifelte ich, daß die Abbildungen von Sowinskys St. bosphorana mit Sicherheit einer bereits bestehenden Art zugeschrieben werden können. Erst die Hilfe unseres Freundes Prof. Dr. Gerolf Lampel, Fribourg, der mir die Beschreibung völlig übersetzte, überzeugte mich von der oben angegebenen Synonymie.

Diese Art wurde auch von Chevreux nur unvollständig abgebildet, vor allem fand er kein Männchen, sodaß eine komplette Neubeschreibung sowie vollständige Zeichnungen hier berechtigt erscheinen.

In der Folge wird ein "S" die Angaben von Sowinsky wiedergeben, ein „K" über meine eigenen Daten aussagen.

Beschreibung. -

$\delta$ : Länge 3,49 mm (S); $4 \mathrm{~mm}(\mathrm{~K})$.

Erste Antenne: die ersten 2 Pedunculusglieder etwa gleich lang (S); 1 . Glied $3 / 4$ des 2 . Gliedes (K: Abb. 22); 3. Glied kleiner als $1 / 3$ des 2. Gliedes (S, K). Alle Pedunculusglieder kahl. Flagellum 


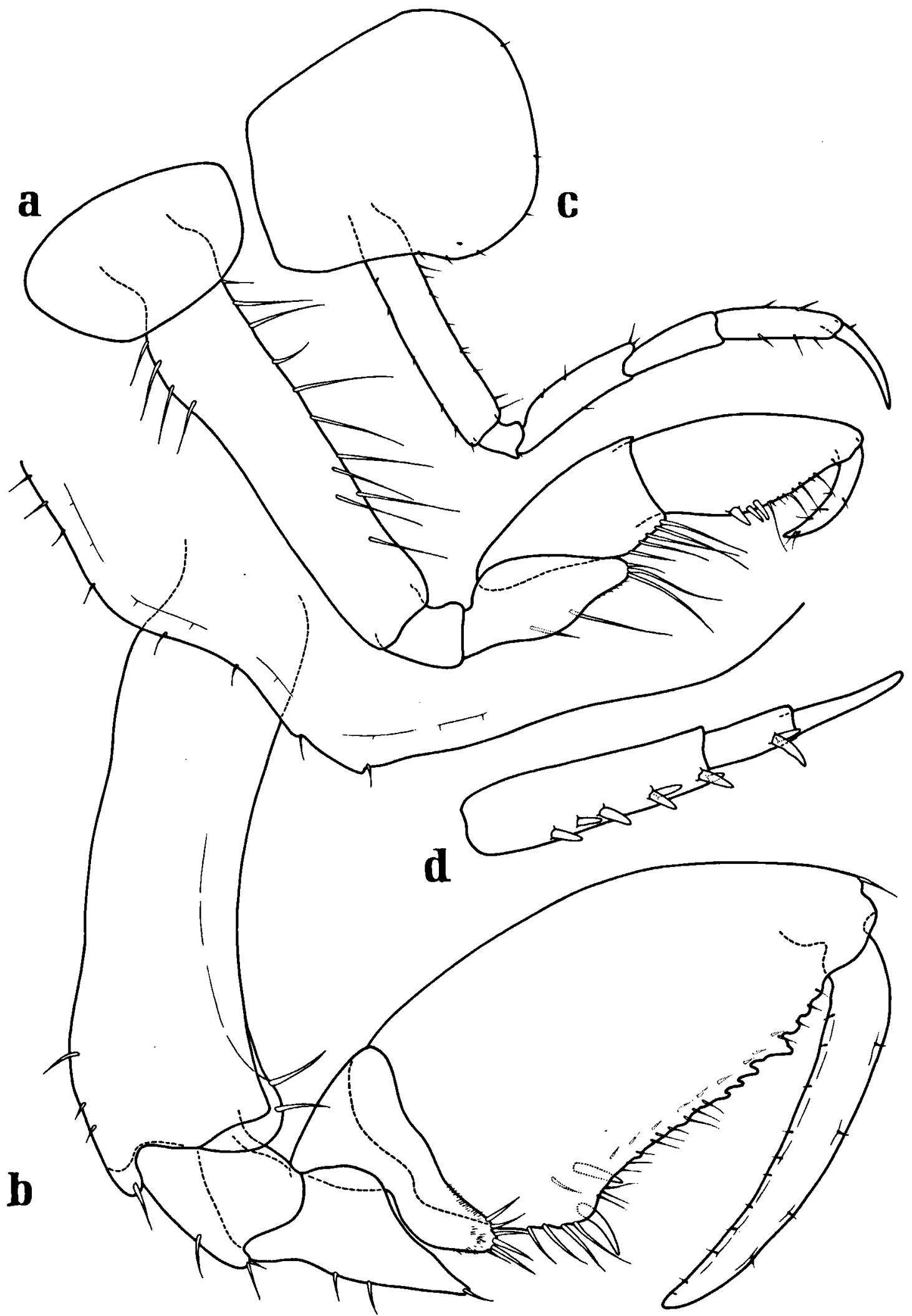

Abb. 23. Stenothoe bosphorana Sowinsky, 1898. a, Gn1 q; b, Gn2 \&; c, P3 § ; d, U3 ठ . 

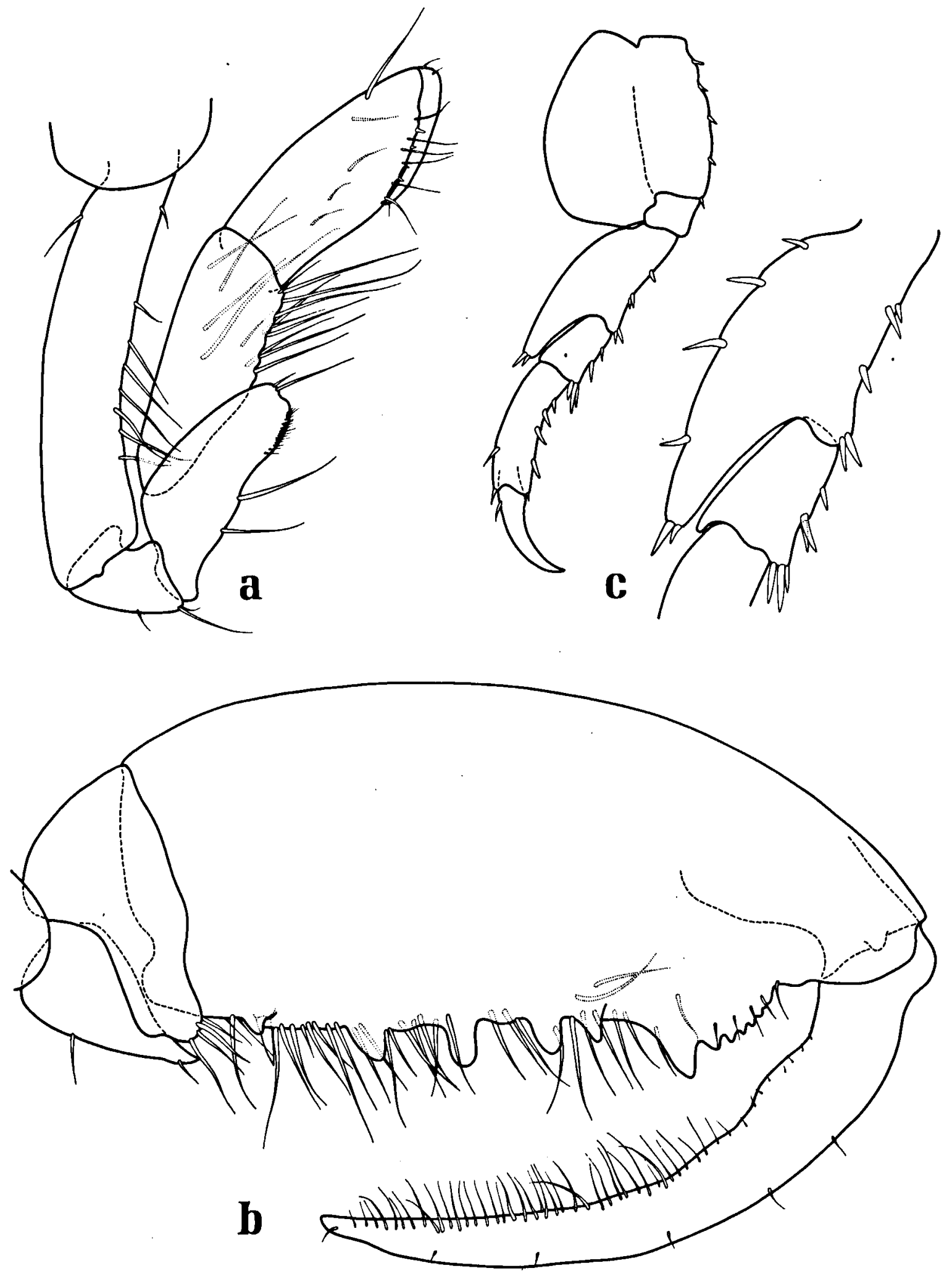

Abb. 24. Stenothoe bosphorana Sowinsky, 1898. a, Gn1 o; b, Gn2 o, distal; c, P7 đo, rechts Detail vergrößert. 


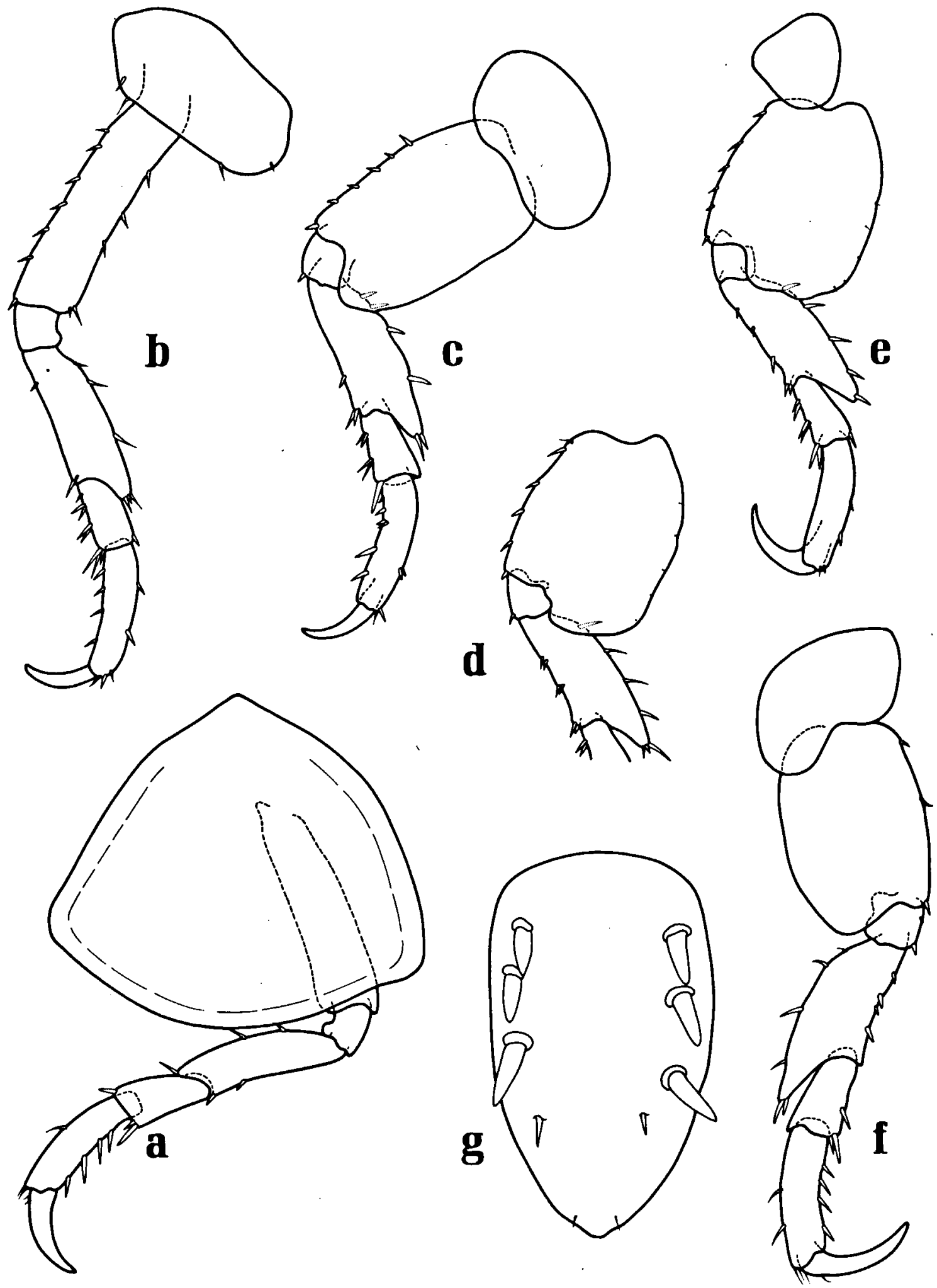

Abb. 25. Stenothoe bosphorana Sowinsky, 1898. a, P4 §̊; b, P5 ९; c, P6 ९; d-e, P7 ९, links und rechts etwas verschieden; $\mathrm{f}, \mathrm{P} 6 \delta ; g$, Telson. 
11-12 gliedrig (S), 20-27 gliedrig (K). Die ersten Geißelglieder tragen lange und dünne Riechhaare (S: Taf. XII Abb. 9a; K: Abb. 22). Eine Nebengeißel $(! ?, S)$ ist kaum zu bemerken und besteht aus einem Glied mit einer Borste (K: nicht zu finden).

Zweite Antenne: Pedunculus viel lānger als Flagellum (S, K), vor allem durch langes 4. und 5. Glied. Flagellum kürzer als letztes Pedunculusglied, 7-8 gliedrig (S, K).

Mundteile: wie für Gattung charakteristisch (S, K).

Gnathopod 1: im Vergleich zu dem zweiten sehr schwach entwickelt. Der schmale, ovale Propodus hat gleiche Länge mit dem Carpus (S: Taf. XII Abb. 13, K: Abb. 22, 23a \& 24a). Die Palma geht ohne scharfe Grenze in den Hinterrand des Propodus über ( $\mathrm{S}, \mathrm{K})$. Der Merus ist etwas kürzer als der Carpus (S, K). Der distale Hinterrand ist außer von Borsten noch von zahlreichen Wimperhaaren bedeckt (S, K). Die Basis ist lang und dünn.

Gnathopod 2: der außerordentlich stark entwickelte Propodus bildet beinahe die Hälfte der ganzen Extremität (S: Taf. XII Abb. 14; K: Abb. 22 \& 23b). Der Hinterrand, der vollständig als Palma angesehen werden kann, ist in seinem distalen Teil leicht gebogen (S, K). Palma wie Dactylus-Innenseite sind dicht beborstet. Zu den auffallendsten Merkmalen dieser Art gehört die Gestaltung der Palma: in der Nähe des Dactylusansatzes liegt ein starker, gezähnter Kamm, dessen äußerer (proximaler) Zahn besonders hervortritt. Längs der übrigen Palma befinden sich 4 Zähne (S), die gleichweit voneinander entfernt liegen (K: fünf Höcker).

Peraeopoden 3-4: untereinander ähnlich, zart. Dactylus dünn, gekrümmt, $2 / 3$ des Propodus $(\mathrm{S}, \mathrm{K})$. Der distale Merusrand bildet einen dreieckigen Lappen (S, nicht $\mathrm{K}$ ), der sich beinahe auf ein Drittel der Länge des folgenden Gliedes hinzieht.

Peraeopoden 5-7: die Basis von P5 schlank wie die vorhergehenden, bei $\mathrm{P} 6$ und $\mathrm{P} 7$ robust gerundet. Distaler Hinterrand des Merus zu dreieckigem Lappen ausgezogen, der sich bei P7 auf $3 / 3$ des folgenden Gliedes (S) hinzieht (K: erreicht Unterrand von Carpus, siehe Abb. 22, wie auch Chevreux \& Fage, 1925: 136, Abb. 135).

Uropoden: beim 1. Paar (S: Taf. XII Abb. 19) sind Äste und Schaft gleich lang (S). Das 2. Paar ist halb so lang wie das erste. Uropod 3 (S: Taf.
XI Abb. 24) ist einästig. Basis mit 3 starken Dornen bewehrt. Erstes Astglied ebenfalls mit 3 Dornen, letztes nackt und krallenähnlich (S).

Telson: (S: Taf. XI Abb. 23) verlängerte, dachförmig gebogene Platte mit Rückenkiel und abgestumpfter Spitze. In der vorderen Hälfte mit 2 Paar Stacheln (S), in der hinteren mit 2 Paar Härchen besetzt (K: 3 Paar Stacheln).

\section{९: Länge 3,54 mm (S); $4 \mathrm{~mm}(\mathrm{~K})$..}

Erste Antenne deutlich länger als zweite im Gegensatz zur Antennenproportion des $\sigma(S)$.

Gnathopod 1: Carpus fast $1 / 2$ des Propodus (S); kaum kürzer als Propodus (K: Abb. 23a). Letzterer etwas breiter, bauchiger als beim $\delta(S, K)$. Basis relativ kürzer als beim $\succsim(\mathrm{S}$; K: etwa gleich wie $\Varangle)$, etwa gleich der Hälfte der Gesamtextremität.

Gnathopod 2: Propodus etwa mandelförmig mit einem fast geradlinigen vorderen Rand und einer konvexen Handfläche (S; K: Palma fast gerade, beinahe etwas konkav, Abb. 23b). Palma nimmt etwa die Hälfte des Propodushinterrandes (S; K: fast gesamten Hinterrand) ein, wird durch zwei Stacheln abgegrenzt (S, K).

Peraeopod 7: dreieckiger Lappen des Merus ist schwächer entwickelt und kürzer als beim $\delta$.

\section{Diskussion. -}

Stenothoe bosphorana läßt sich leicht von den anderen Arten im Mittelmeer (ausgenommen $\boldsymbol{S t}$. antennulariae, siehe dort) durch den ersten Gnathopoden unterscheiden, dessen Merus den Carpus nur zur Hälfte, höchstens zu $2 / 3$ überlappt. Dieses Merkmal findet man bei Männchen wie Weibchen sowie auch bei Juvenilformen.

Dagegen ist das Merkmal, welches Chevreux \& Fage, 1925, im Bestimmungsschlüssel verwenden, nämlich das Herabreichen des Carpus über den Merus bis zum Propodusansatz beim letzten Peraeopoden, weder bei Juvenilformen noch bei den Weibchen deutlich genug ausgeprägt, sodaß durch diese Eigenschaft allein eine Abtrennung von St. marina nicht zweifelsfrei möglich ist.

Die Zeichnungen wurden nach eigenem Sammlungsmaterial aus Dalmatien angefertigt.

Verbreitung. -

Azoren, 1919 m. Mediterran: Saint-Tropez, $50 \mathrm{~m}$; Tunesien, $170 \mathrm{~m}$, Schlamm; Dalmatien (Insel Zlarin), 111-197 m, Schlamm; Bosporus, 35 m. 
Stenothoe marina (Bate, 1857).

Stenothoe marina; Sars, 1892: 236, Taf. LXXX; Chevreux \& Fage, 1925: 136-137, Abb. 136.

Stenothoe marina ssp. mediterranea Ledoyer, 1973: 894, Abb. $12-13$.

Das einzige Zitat aus dem Mittelmeer für über 100 Jahre blieb Hellers Art Probolium marinum (Heller, 1866: 14), die von Stebbing, 1906, mit Stenothoe marina in Synonymie gesetzt wurde. Von diesem Material existiert dagegen kein Beleg mehr (Krapp-Schickel, 1974), es wurde keine Zeichnung angefertigt, und der Text sagt aus, $\mathrm{da}$ es sich um ein einziges Weibchen handelte, dessen „beide Fußpaare in ihrer Stärke und Form wenig verschieden" (Heller, 1866: 14) sind; das „Handglied erscheint in beiden länglicheiförmig, der untere Rand fast ohne Unterbrechung. .." (op. cit.: 15). Es ist wahrscheinlich, daß Heller keine Stenothoe marina vor Augen hatte.

Chevreux \& Fage, 1925, zitieren diese Art ausschließlich aus dem Atlantik.

Erst Ledoyer, 1973, bildet ein Männchen von Stenothoe marina aus Gorgonien der Umgebung von Marseille $a b$, das ihm jedoch von atlantischen Exemplaren (nach Studium der Abbildungen in Sars, 1892, und Chevreux \& Fage, 1925) unterschiedlich genug vorkommt, um daraus eine neue Unterart zu machen. Leider gibt Ledoyer nicht an, nach welchem Materialumfang er diese Unterart aufstellte, doch war er so hilfsbereit, mir sein Material zur Verfügung zu stellen, u. zw. insgesamt $2 \delta$ und $3 \%$ \%

Sein Text-Hinweis (Ledoyer, 1973: 894) auf die Figur eines zweiten Gnathopoden in Della Valle (1893: Taf. LVIII Abb. 79) ist irreführend, da diese zwar tatsächlich, unter dem Namen von $S t$. monoculoides, St. marina abbildet, jedoch nach Sars kopiert ist, wie die Abbildungslegende aussagt. Demnach hatte Della Valle kein napoletanisches Material zur Verfügung und die fünf Tiere aus Marseille bleiben der vorläufig einzige mediterrane Fund.

Sie unterscheiden sich nach Ledoyer, 1973, durch stärkere Bedornung am Telson sowie Pedunculus von U3 von der Nominatform: Sars, 1892, wie Chevreux \& Fage, 1925, bilden am Telson außer einem Borstenpaar zwei Stachelpaare ab, der U3 Pedunculus trägt 4 einzelne Stacheln, am Distalrand ein Stachelpaar. Ledoyers Individuen haben am Telson außer den
Setolae drei Paar Stacheln (bei dem präparierten $\delta$ links noch eine vierte einzelne), am U3 Pedunculus 6 einzelne Stacheln außer dem distalen Stachelpaar.

Dank der Hilfe des British Museum (Natural History), London, und des Universitetets Zoologiske Museum, København, konnte ich sowohl den Typusbeleg wie größere atlantische Serien von Stenothoe marina durchsehen. Das Material stammt von W-Norwegen, Färöer, den Brit. Inseln und W-Afrika. Die Norm trägt 2 Stachelpaare am Telson und 4 einzelne Stacheln am letzten Uropoden; doch fand ich sowohl in der Sammlung von Sars aus W-Norwegen, wie in der von Norman aus Plymouth und unter den Individuen aus W-Afrika offensichtlich hyperadulte Tiere, die etwas größer als die übrigen waren und 3 Dornen oder Stacheln am Telson sowie 5 einzelne Stacheln außer dem randlichen Paar am letzten Uropodenpedunculus trugen. Der Ubergang zu den 3-4 Stacheln am Telson und 6 am dritten Uropoden im mediterranen Material ist demnach gleitend, sodaß ich meine, daß dies allein kein stichhaltiges Kriterium für eine neue Unterart sein kann.

Erwähnt werden sollte noch, daß im mediterranen Material bei beiden Geschlechtern der Merus von Gn2 mit einer sichelförmigen Spitze noch über den Propodusansatz hinausgezogen ist (cf. Ledoyer, 1973, Abb. 12), während bei dem atlantischen Material die distale Merusspitze weniger gekrümmt und auch etwas kürzer ist. Aber dies ist als Abtrennungsmerkmal sicher ebenfalls nicht schwerwiegend genug.

Verbreitung. -

Atlantik: Norwegen, Färöer, Brit. Inseln, Helgoland, Spanien, Portugal, Azoren, Bermuda Inseln, W-Afrika. Mediterran: Marseille.

\section{BESTIMMUNGSSCHLUSSEL ZU DEN MEDITERRANEN} VERTRETERN DER GATTUNG STENOTHOE

1a. Telson ohne Stacheln, nur mit Borsten oder ganz nackt .............. 2

b. Telson deutlich bestachelt ......... . 5

2a. Gnathopod $2 \delta$ mit deutlich abgesetzter Palmarkante etwa in der Halfte der Propodushinterkante. Palma zweifach tief halbkreisförmig eingekerbt; maximal $2 \mathrm{~mm}$ Körperlänge . . Stenothoe cavimana ơ (Abb. 7-8)

b. Gnathopod 2 mit glatter Propodushinterkante . 3

3a. U3 Pedunculus nackt oder mit einem schwachen Dorn, Ast am Ende des ersten Gliedes mit 1 Borste oder Dorn, 
keine Stacheln. Hinterkante der Basis von P6 bei Juvenilen wie P5 (!), bei Adulten bis etwa zur Hälfte gradlinig, oft parallel zur Vorderkante verlaufend, erst dann verbreitert sie sich plötzlich bauchig; bei Hyperadulten gleitender Ubergang. Basis von P6 und P7 deutlich länger als Merus + Ischium. Merus auffallend schlank. Ov. \& mit 2-4 großen Eiern. GrobsandBewohner geringer Tiefe. Länge $1-1,5 \mathrm{~mm}$. . . .

. . . Stenothoe elachista n. sp. $\delta$, 9 (Abb. 4-6)

b. U3 Pedunculus mit 1 bis mehreren Dornen, Basis von P6 immer bauchig, ähnlich wie P7. Ov. $q$ selten kleiner als $1,5 \mathrm{~mm}$............. 4

4a. Gnathopod $2 \delta$, $\uparrow$ (bei reifen Individuen manchmal auch Gnathopod $1 \delta$, $)$ ) durch Stachelgruppe und stumpfen Winkel stark abgesetzte Palmarkante. Gedrungener Körperbau. Ov. \& mit 7-21 kleinen Eiern. Algen- und Sedimentbewohner. Lãnge 2-3 mm

. . . . . Stenothoe monoculoides $\delta$, 9 (Abb. 3)

b. Gnathopod 1 und 2 mit harmonischem Verlauf, beide schwach bestachelt, schlanke und schwache Basen. Zarter Körperbau. Schwammbewohner. Länge max. 2 $\mathrm{mm}$. . . . . Stenothoe cavimana $\$$ (Abb. 7-8)

5a. Carpus von Gnathopod 1 nur bis zur Hälfte oder weniger von Merus überlappt; restliche Hinterkante parallel zu Vorderkante . . . . . . . . . . . 6

b. Carpus von Gnathopod I ohne parallele Vorder- und Hinterkante, dreieckig mit abgerundeter Hinterkante 7

6a. Körper robust, rundlich; Antennen kurz und kräftig. Merus von P7 breit ausladend, erreicht bei $\delta$ wie $q$ nicht das distale Carpusende. Propodushinterkante von Gnathopod 2 bei $\delta$ wie $q$ konvex, harmonisch gerundet. Hydroidenbewohner. Länge ov. $\$ 1,5 \mathrm{~mm}$... .

. . . . Stenothoe antennulariae o, \& (Abb. 9-10)

b. Lange, schlanke Antennen. P7 adulter $\delta:$ Merus bis zu distalem Carpusende herabgezogen, Propodushinterkante von Gnathopod 2 , $\%$ gerade oder etwas konkav eingebuchtet. Schlammbewohner. Lānge ov. 9 3-4 $\mathrm{mm}$. . . Stenothoe bosphorana $\delta, ~ \$$ (Abb. 22-25)

7a. Gnathopod 2 \&, 9 mit gleichmäßig ovaler Hinterkante, ohne Einkerbung oder vorspringenden Zahn, mit wenigen Stacheln und Dornen besetzt . . . . . .

....... Stenothoe tergestina $\delta^{\circ}$, (Abb. 1-2)

b. Gnathopod $2 \delta$ mit Einkerbung und Zahn oder Zähnen am Distalende der Palmarkante. Oder keine $\delta \delta$ zur Verfügung ............ 8

8a. Coxa 2 bei $\delta$ wie $q$ Vorderkante nicht gleichmäßig konvex, sondern etwas eingebuchtet. Merus von $\mathrm{P} 7$ vor allem beim $\delta$ auffallend breit ausladend, Vorderkante etwa gleich lang wie die Breite. Gnathopod 2 o an distaler Propodushinterkante mit einem kleinen Zahn

. . . . . . Stenothoe valida o, \& (Abb. 19-21)

b. Coxa 2 mit gleichmäßig konvexer Vorderkante. Merusvorderkante von $P 7$ lānger als die Breite . . . . 9

9a. Propodushinterkante $\mathrm{Gn} 2$ ठ ziemlich regelmäßig über die ganze Länge, Gn2 $q$ über $4 / 3$ der Länge gesägt oder gekerbt. Merus P7 nie bis zum Propodusansatz herabreichend; Merus Gnl dagegen immer wenigstens $1 / 4$ des Carpus überlappend . . . Stenothoe marina $\delta$, $\%$

b. Propodushinterkante von $\mathrm{Gn} 2$ o nur am Distalende gezähnt, Großteil der Palma glatt; Propodushinterkante Gn2 \& entweder völlig glatt, mit einer halbkreisförmigen Vertiefung oder einem einzigen Höcker am distalen
Drittel ..................... 10

10a. $\delta$ zur Verfügung . . . . . . . . . 11

b. $\$$ zur Verfügung . . . . . . . . . . 13

11a. Letztes Glied von Uropod 3 o deutlich gekrümmt, Innenkante stark gesägt; Telson wie Peraeopoden reich bestachelt. Merus von P5-P7 distal etwa doppelt so breit wie Carpus. Oberflächenbewohner . . . . . . . . . . . . . Stenothoe gallensis ơ (Abb. 14-16)

b. Letztes Glied von Uropod 3 đ kaum gekrūmmt, höchstens leicht geschwungen. Innenkante schwach oder überhaupt nicht gesägt. Telson wie Peracopoden spärlich bestachelt. Merus von P5-P7 schlank, kaum verbreitert gegenüber dem Carpus. Fast stets unterhalb von $5 \mathrm{~m}$ Tiefe anzutreffen . . . . . . . 12

12a. Dactyli von P5-P7 deutlich lānger als der halbe Propodus. Schwamm- und Aszidienbewohner . . . . . . . . . . Stenothoe eduardi n. sp. ठ (Abb. 18)

b. Dactyli von P5-P7 nicht länger als der halbe Propodus. Algenbewohner. . Stenothoe dollfusi o (Abb. 12-13)

13a. Ov. \& mit deutlicher, tiefer, halbkreisförmiger Einkerbung am Distalende der Palma

. . . . . . Stenothoe dollfusi $q$ (Abb. 11-13)

b. Ov. $\$$ ohne Einkerbung . . . . . . . 14

14a. Ov. \& meistens mit einem Zahn an dem distalen Propodusende. Bewohner von Schwämmen und Aszidien. In der Regel unterhalb von $10 \mathrm{~m}$ Tiefe

Stenothoe eduardi n. sp. $९$ (Abb. 17)

b. Ov. $q$ stets ohne Zahn. Bewohner von Algen der obersten Küstenmeter . . . . . . . Stenothoe tergestina $\%$, Stenothoe gallensis $\$$ (Abb. 1-2; 14-16)

\section{LITERATUR}

Barnard, J. L., 1955. Gammaridean Amphipoda (Crustacea) in the collections of Bishop Museum. Bull. Bernice P. Bishop Mus., 215 : 1-46, Abb. 1-20.

-, 1958. Index to the families, genera, and species of the gammaridean Amphipoda (Crustacea). Occ. Pap. Allan Hancock Fdn., $19: 1-145$.

-, 1974. Gammaridean Amphipoda of Australia, part II. Smithson. Contr. Zool., 139 : i-v, 1-148, Abb. 1-83.

Bellan-Santini, D. \& M. Ledoyer, 1973. Inventaire des Amphipodes gammariens récoltés dans la région de Marseille. Téthys, 4(4) : 899-934.

CAtTA, J. D., 1876. Note sur quelques Crustacés erratiques. Annls. Sci. nat., (6) 3 (1) : 1-33, Taf. I-II.

Cecchini, C. \& P. Parenzan, 1935. Anfipodi del Golfo di Napoli. Pubbl. Staz. zool. Napoli, 14 (2) : 153-250, Abb. $1-55$.

Chevreux, E., 1887. Catalogue des Crustacés Amphipodes marins du Sud-Ouest de la Bretagne, suivi d'un aperçu de la distribution géographique des Amphipodes sur les côtes de France. Bull. Soc. zool. Fr., 12 (2-4) : 288-340, TextAbb. 1-8, Taf. V.

-, 1891. Quatrième campagne de l'Hirondelle, 1888. Hyale grimaldii et Stenothoe dollfusi. Bull. Soc. zool. Fr., 16 : 257-262, Abb. 1-10.

,- 1900 . Amphipodes provenant des campagnes de l'Hirondelle (1885-1888). Résult. Camp. scient. Prince Albert I, 16 : i-iv, 1-195, Taf. I-XVIII. 
- 1907. Diagnoses d'Amphipodes nouveaux recueillis dans les possessions françaises de l'Océanie par M. L. Seurat, directeur du Laboratoire de recherches biologiques de Rikitea. Bull. Mus. natn. Hist. nat. Paris, $13(6): 412-417$.

-, 1908a. Description de deux nouvelles espèces d'Amphipodes des parages de Monaco. Bull. Inst. océanogr. Monaco, $113: 1-8$, Abb. $1-6$.

-, 1908b. Diagnoses d'Amphipodes nouveaux provenant des campagnes de la Princesse-Alice dans l'Atlantique Nord (suite). Stenothoidae/Oediceridae/Tironidae. Bull. Inst. océanogr. Monaco, $129: 1-12$, Abb. 1-6.

,$- 1908 \mathrm{c}$. Amphipodes recueillis dans les possessions françaises de l'Océanie par M. le Dr. Seurat, Directeur du Laboratoire de recherches biologiques de Rikitea (îles Gambier), 1902-1904. Mém. Soc. zool. Fr., 20 (4) : 470—527, Abb. 1-35.

-, 1911. Campagnes de la Melita. Les Amphipodes d'Algérie et de Tunisie. I. Gammarina. Mém. Soc. zool. Fr., 23 (3-4) : 145-285, Text-Abb. 1-17, Taf. VI-XX.

-, 1913. Sur quelques intéressantes espèces d'Amphipodes provenant des parages de Monaco et des pêches pélagiques de la Princesse-Alice et de l'Hirondelle II en Méditerranée. Bull. Inst. océanogr. Monaco, 262 : 1-26, Abb. $1-9$.

Chevreux, E. \& L. Fage, 1925. Amphipodes. Faune de France, 9 : 1-488, Abb. 1-438 (Lechevalier, Paris).

CostA, A., 1857. Ricerche sui Crostacei Amfipodi del regno di Napoli. Memorie R. Accad. Sci. mat. nat. moral. Napoli, 1 : 165-235, Taf. I-IV.

Della Valle, A., 1893. Gammarini del Golfo di Napoli. Fauna Flora Golf. Neapel, 20 : i-xi, 1-948, [i-liv], Taf. I-LXI.

Heller, C., 1866. Beiträge zur näheren Kenntniss der Amphipoden des Adriatischen Meeres. Denkschr. Akad. Wiss. Wien (math. naturw. Cl.), 26 (2) : I-62, Taf. I-IV.

Krapp-SChickel, G., 1969. Zur Okologie der Amphipoden aus dem Phytal der Nordadria. Zool. Jb. (Syst.), 96 (3) : 265-448, Text-Abb. I-32, Taf. I-VIII.

-, 1974. Camill Hellers Sammlung adriatischer Amphipoden - 1866 und heute. Annln. naturh. Mus. Wien, 78 : 319-379, Abb. 1-28.

LEDOYER, M., 1973. Amphipodes gammariens nouveaux ou peu connus de la région de Marseille. Téthys, 4 (4): 881-898, Abb. 1-13.

Monod, T., 1937. Missions A. Gruvel dans le Canal de Suez. 1. Crustacés. Mém. Inst. Égypte, $34: 1-19$.

NebesKI, O., 1880. Beiträge zur Kenntniss der Amphipoden der Adria. Arb. zool. Inst. Univ. Wien, 3 (2) : 1-52, Taf. X-XIII.

REID, D. M., 1951. Report on the Amphipoda (Gammaridea and Caprellidea) of the coast of Tropical West Africa. Atlantide Rep., 2 : 189-291, Abb. 1-58.

RuFro, S., 1946. Studi sui Crostacei Anfipodi. XI. Gli Anfipodi bentonici di Rovigno d'Istria. Boll. Soc. ent. ital., 76 (7-8) : 49-56, 1 Karte.

-, 1969. Studi sui Crostacei Anfipodi. LXVII. Terzo contributo alla conoscenza degli Anfipodi del Mar Rosso. Memorie Mus. civ. Stor. nat. Verona, 17: 1-77, Abb. $1-24$.

RUFFo, S. \& W. WIESER, 1952. Untersuchungen über die algenbewohnende Mikrofauna mariner Hartböden. 11. Osservazioni sistematiche ed ecologiche su alcuni Anfipodi delle coste mediterranee italiane. Memorie Mus. civ. Stor. nat. Verona, $3: 11-30,1 \mathrm{Abb}$.

SARS, G. O., 1890-1895. An account of the Crustacea of Norway with short descriptions and figures of all the species. Vol. I. Amphipoda: i-viii, 1-711, i-xiii, Taf. I-CCXL, Suppl.-Taf. I-VIII.

SChellenberG, A., 1936. The fishery grounds near Alexandria 10. Amphipoda benthonica. Notes Mem. Fish. Res. Dir. Cairo, 18 : 1-27, 1 Text-Abb., 8 Karten.

-, 1942. Krebstiere oder Crustacea. IV: Flohkrebse oder Amphipoda. Tierw. Dtl., 40 : i-iv, 1-252, Abb. 1-204.

SCHIECKE, U., 1973. Ein Beitrag zur Kenntnis der Systematik, Biologie und Autökologie mariner Peracarida (Amphipoda, Isopoda, Tanaidacea) des Golfes von Neapel: $1-408$, Taf. I-XCI (Inaug. Diss. math. naturwiss. Fak. Christian Albrechts Univ., Kiel).

Shoemaker, C. R., 1935. The amphipods of Porto Rico and the Virgin Islands. Scient. Surv. P. Rico, 15 (2) : 229-262, Abb. 1-5.

SowINSKY, W., 1898. Vysshiya rakoobraznyya (Malacostraca) Bosfora, po materialam" sobrannym" d-rom" A. A. Ostroumovym"' v" 1892 i 93 gg. I. Amphipoda i Isopoda. [Les Crustacés supérieurs (Malacostraca) de Bosphor, après les matériaux recueillis par Mr. le Dr. A. A. Ostrooumow en 1892 et 1893. I. Amphipoda et Isopoda]. Zap. kiev. Obshch. Estest., 15 (2) : 447-518, Taf. VIII-XIII.

Stebring, T. R. R., 1906. Crustacea Amphipoda. I. Gammaridea. Tierreich, 21 : i-xxxix, 1-806, Abb. 1-127.

Stephensen, K., 1949. The Amphipoda of Tristan da Cunha. Results Norw. scient. Exped. Tristan da Cunha, $19: 1-61$, Abb. 1-23.

Walker, A. O., 1904. Report on the Amphipoda collected by Professor Herdman, at Ceylon, in 1902. In: W. A. HERDMaN, Report to the Government of Ceylon on the pearl oyster fisheries of the Gulf of Manaar, with supplementary reports upon the marine biology of Ceylon, by other naturalists. Part II (Supplementary Reports, No. XVII): 229-300, Taf. I-VIII (Royal Society, London). 